\title{
Ohne Satz vom Widerspruch keine Entität - der Satz vom Widerspruch als Strukturformel der Realität ${ }^{1}$
}

\author{
Gianluigi Segalerba (Universität Wien)
}

This paper deals with some aspects of the strategy of defence that Aristotle dedicates to the principle of contradiction; the analysis is focussed on a number of passages of the chapter Metaphysica Gamma 4. The main thesis of the paper is that Aristotle's strategy consists in an ontological defence of the principle itself: the principle is being defended on the basis of the unacceptable consequences which would arise for the ontology in case of the absence of the principle itself. Among these consequences are, for instance, the disappearance of properties, of essences, of individual entities and of the plurality of essentially distinguishable entities, since the contents of the properties, the role of properties as essences and the constitution of the individual entities cannot hold good, if the principle of contradiction does not hold good. The adversary of the principle of contradiction will be thus caught in the dilemma of either accepting the validity of the principle of contradiction or refusing the principle and, with it, the reality itself. The principle of contradiction appears to be, therefore, the ontological presupposition of the whole reality; it is the principle on which the whole reality depends: it shows itself to be not only a logic law, but also, and more than this, the ontological presupposition for every kind of entity: without the principle of contradiction there is no entity. The paper follows Aristotle in his search for instruments in favour of the defence of the principle of contradiction; these instruments are, in the end, elements of the reality itself, such as properties, essences and individual entities: since the disappearance of properties, of essences and of individual essences, which would arise as a result of the collapse of the principle of contradiction, cannot be accepted, the principle of contradiction must conserve its validity.

\footnotetext{
${ }^{1}$ Ich möchte mich desgleichen bei Frau Kathrin Bouvot, BA, BA, für die Korrektur des Textes und für die äußerst wichtigen Bemerkungen, welche den Inhalt meiner Arbeit zweifelsohne durchaus verbessert haben, ganz herzlich bedanken. Die Verantwortung für die Inhalte und die Auffassungen, welche ich in dieser Studie zur Entfaltung bringe, liegt selbstverständlich bei mir.
} 
Journal of Ancient Philosophy Vol. V 2011 Issue 2

a) Einführung

Der Angriff gegen den Satz vom Widerspruch und dessen Verteidigung in Metaphysica Gamma ${ }^{2}$ bilden eines der anregendsten und hinreißendsten Duelle, die im ganzen Werk des Aristoteles zu lesen sind; denn der Kampf, welcher in Metaphysica Gamma vor unseren Augen stattfindet, ist nicht nur ein Kampf zur Verteidigung des Satzes vom Widerspruch: Er ist - bei genauerem Hinsehen - ein Krieg zur Verteidigung der ganzen aristotelischen Ontologie und der Möglichkeit der Realität. Der vorliegende Text soll einige Stellen der Verteidigungsstrategie des Aristoteles mit besonderer Berücksichtigung für einige Aussagen analysieren, welche in Metaphysica Gamma 4 enthalten sind; das Ziel dieser Untersuchung besteht darin, zu verdeutlichen, dass der Angriff seitens des Gegners der Gültigkeit des Satzes vom Widerspruch eine so große Bedrohung für das Bestehen und den Zusammenhalt der Ontologie repräsentiert, dass Aristoteles dazu gezwungen ist, zur Verteidigung des Satzes die zentralen Themen

\footnotetext{
${ }^{2}$ Die altgriechischen Ausgaben der aristotelischen Werke, die ich in dieser Arbeit verwendet habe, sind die Folgenden: für die Categoriae und De Interpretatione die Ausgabe von L. MinioPaluello (Aristotelis Categoriae et Liber De Interpretatione. Recognovit Brevique Adnotatione Critica Instruxit L. Minio-Paluello, Clarendon Press, Oxford 1949 (1), 1992 (10)); für die Analytica Posteriora die Ausgabe von W. D. Ross, welcher ein Anhang von L. Minio-Paluello beigefügt wurde (Aristotelis Analytica Priora et Posteriora, Recensuit Brevique Adnotatione Critica Instruxit W. D. Ross, Praefatione Et Appendice Auxit L. Minio-Paluello, Clarendon Press, Oxford 1964); für die Metaphysica die Ausgabe von W. D. Ross (Aristotle's Metaphysics, A Revised Text with Introduction and Commentary, Clarendon Press, Oxford 1924) und die Ausgabe von W. Jaeger (Aristotelis Metaphysica, Recognovit Brevique Adnotatione Critica Instruxit W. Jaeger, Clarendon Press, Oxford 1957); für die Schrift „De Anima" die Ausgabe von R. D. Hicks (Aristotle, De Anima, with Translation, Introduction and Notes by R. D. Hicks, Cambridge University Press, Cambridge 1907; Georg Olms Verlag, Hildesheim · Zürich · New York 1990. Nachdruck der Ausgabe Cambridge 1907), die Ausgabe von W. Biehl und O. Apel (Aristoteles, Über die Seele. Mit Einleitung, Übersetzung (nach W. Theiler) und Kommentar herausgegeben von Horst Seidl. Griechischer Text in der Edition von Wilhelm Biehl u. Otto Apel, Felix Meiner Verlag, Hamburg 1995), und die Ausgabe von W. D. Ross (Aristotelis De Anima, Recognovit Brevique Adnotatione Instruxit W. D. Ross, Clarendon Press, Oxford 1956); für die Topica die Ausgabe von W. D. Ross (Aristotelis Topica Et Sophistici Elenchi, Recognovit Brevique Adnotatione Critica Instruxit W. D. Ross, Oxford 1958 (1). Reprinted from corrected sheets of the first edition 1963, with further corrections 1970, Clarendon Press, Oxford 1970).
} 
Journal of Ancient Philosophy Vol. V 2011 Issue 2

seiner Ontologie zu verwenden ${ }^{3}$. Die Formel, welche meine Interpretation zum Ausdruck bringt, ist die Folgende:

Ohne Satz vom Widerspruch keine Entität.

Die Benutzung dieser Formel lässt sich dadurch rechtfertigen, dass, da ohne Satz vom Widerspruch jedes ontologische Element von widersprüchlichen Merkmalen gekennzeichnet wird, als eine Konsequenz davon jedes ontologische Element zugrunde geht; es liegt infolgedessen in dieser Konstellation keine Entität mehr vor: Es werden z.B. weder Eigenschaften noch Einzelentitäten vorhanden sein können, da der Inhalt von jedweder Eigenschaft und konsequenterweise die Essenz jeglicher Einzelentität wegen der Anwesenheit von widersprüchlichen Elementen in jeder Eigenschaft verloren gehen; die ganze Realität verschwindet ${ }^{4}$.

Aristoteles ist sich selbst meiner Meinung nach völlig davon bewusst, dass die Wichtigkeit, Unentbehrlichkeit und Unabdingbarkeit der Verteidigung des Prinzips aller Prinzipien - wie der Satz vom Widerspruch bezeichnet werden kann - so entscheidend und gleichzeitig die Bedrohung und die Gefahr für dessen Gültigkeit so enorm sind, dass die Verteidigung des Satzes vom Widerspruch nach grundlegenden, nach den grundlegendsten Argumenten verlangt. Der Ernst der Stunde ${ }^{5}$ erfordert gleichsam das Beste, das Primäre, das Umfassendste der aristotelischen Ontologie: Denn für alle Einzelentitäten gilt - unter anderem - infolge des Satzes vom Widerspruch, dass sie

\footnotetext{
${ }^{3}$ Definitionen und Erklärungen von bestimmten Konzepten und in dieser Hinsicht von meiner besonderen Benutzung von bestimmten Konzepten wie Einzelentität, Entität, Eigenschaft, Essenz und so weiter sind im 2. Paragraphen dieser Studie zu finden.

${ }^{4}$ Eine der Schwierigkeiten, die in der Verteidigungsstrategie vorliegt, welche von Aristoteles dem Satz vom Widerspruch gewidmet wird, besteht - zumindest meiner Ansicht nach - darin, dass Aristoteles gleichzeitig sowohl von Eigenschaften wie auch von Einzelentitäten spricht, ohne dass er die zwei Bereiche in den zahlreichen Argumentationen, die er anstellt, voneinander unterscheidet; er geht hingegen stets von einem Bereich zum anderen und umgekehrt über. Meiner Meinung nach erweist es sich in dieser Hinsicht als nicht immer leicht, zu verstehen, welchen Bereich von Entitäten Aristoteles jeweils berücksichtigt. Es sollte desgleichen in diesem Zusammenhang darauf hingewiesen werden, dass es umstritten sein kann, ob einerseits die Legitimität des Verfahrens des Aristoteles, d.h. beide Bereiche der Entitäten zugleich zu verwenden, immer verteidigt werden kann, und ob andererseits die Stichhaltigkeit von Aristoteles' Strategie immer vertreten werden kann.

${ }^{5}$ Es liegen sozusagen eine feste Proportion und eine enge Korrespondenz zwischen dem Ernst des Angriffes und den Instrumenten vor, welche gegen den Angriff benützt werden.
} 
Journal of Ancient Philosophy Vol. V 2011 Issue 2

keine Eigenschaften haben können, welche ihrem konstitutiven, d.h. wesentlichen Inhalt zuwiderhandeln; der Zerfall des Satzes vom Widerspruch würde jedoch genau bedeuten, dass jegliche Einzelentität Eigenschaften haben kann, welche gegen ihre eigenen wesentlichen Eigenschaften verstoßen. Ferner wird durch das Kollabieren des Satzes vom Widerspruch auch der Inhalt von jedweder Eigenschaft vernichtet, da der Inhalt jedweder Eigenschaft im Falle dieses Kollabierens auch von der Verneinung des Inhaltes selbst begleitet würde. Daher würde der Zusammenfall des Satzes vom Widerspruch die Annullierung jeder Entität qua Entität (d.h. sowohl der Einzelentitäten wie auch der Eigenschaften) mit sich bringen. Der Satz vom Widerspruch ist - wie meiner Meinung nach gesagt werden könnte - gemäß der Formulierung, welche Aristoteles von ihm darlegt (Metaphysica Gamma 5, 1005b19-20):

«Es ist unmöglich, dass dasselbe demselben und in derselben Beziehung gleichzeitig

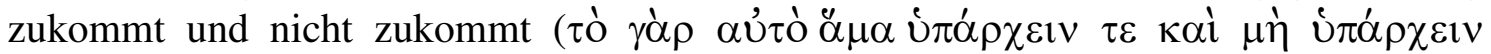

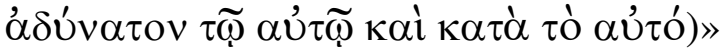

die Strukturformel der Realität ${ }^{6}$, und zwar in dem Sinne, dass der Satz vom Widerspruch die allgemeingültige ontologische Verpflichtung für all die Entitäten der Realität darstellt; der Satz vom Widerspruch ist nämlich die Realität selbst in ihrer tiefen Struktur, weil nach Aristoteles' Einschätzung - die meiner Meinung nach in den von ihm erarbeiteten verschiedenen Argumentationen zugunsten der Verteidigung des Satzes vom Widerspruch lesbar ist -, das Bestehen und der Zusammenhalt der

\footnotetext{
${ }^{6}$ Der Satz vom Widerspruch soll meiner Ansicht nach als die Strukturformel der Realität definiert werden, da er die implizite und unentrinnbare Voraussetzung für die ontologische Konstitution jeder beliebigen Entität ist. Der Satz vom Widerspruch ist die grundlegende Struktur jeder besonderen Entität; er ist sozusagen die Voraussetzungsformel jeder partikulären Formel. Anders gesagt, müssen jede Eigenschaft und dementsprechend jegliche Formel einer Eigenschaft dem Satz vom Widerspruch ,gehorchen“; sie müssen das Diktat des Satzes vom Widerspruch respektieren; jede Formel, welche eine Eigenschaft zum Ausdruck bringt, muss dem Satz vom Widerspruch nachkommen; der Punkt ist jedoch, dass die Eigenschaft selbst noch vor der bestimmten Formel, die sie ausdrückt, den Satz vom Widerspruch respektieren muss. Die Tatsache, dass die Formel, welche eine Eigenschaft zum Ausdruck bringt, den Satz vom Widerspruch respektiert, erweist sich, mit anderen Worten, als eine Konsequenz davon, dass diese nämliche Eigenschaft selbst den Satz vom Widerspruch respektieren muss: Eine Eigenschaft kann nicht Merkmale haben, welche mit ihrem eigenen Inhalt kontrastieren; die Eigenschaft „Mensch-Sein“ kann z.B. nicht Merkmale enthalten, welche den Inhalt der Eigenschaft negieren. Der Wert der Gültigkeit des Satzes vom Widerspruch betrifft zuerst die Realitätsstrukturen und dann die Definitionen der Realitätsstrukturen: Der Satz vom Widerspruch ist das Grundgesetz der Realität.
} 
Journal of Ancient Philosophy Vol. V 2011 Issue 2

Eigenschaften $^{7}$, der Essenzen ${ }^{8}$, des kategorialen Systems ${ }^{9}$, der sich auf das Wesen stützenden wechselseitigen Unterscheidbarkeit der Einzelentitäten ${ }^{10}$ auf den Zusammenhalt und auf die Gültigkeit des Satzes vom Widerspruch angewiesen sind: Es gibt daher offensichtlich einfach kein Morgen, falls der Satz vom Widerspruch fällt; im Falle, dass die Gültigkeit des Satzes vom Widerspruch kollabiert, bedeutet dies das Ende für die ganze Ontologie.

Ein Angriff gegen die Grundlagen der Ontologie, wie es der Angriff gegen den Satz vom Widerspruch ist, erfordert - obwohl dies auf den ersten Blick als seltsam erscheinen kann - das Verwenden der Grundfesten der Ontologie, damit die Verteidigung des Satzes Aussicht auf Erfolg haben kann; es ist meinem Ermessen nach so, dass sich Aristoteles im Kontext der Verteidigung des Satzes vom Widerspruch als Verteidigungsinstrumente genau derjenigen Realitätsstrukturen bedient, welche vom Ausfall der Gültigkeit des Satzes vom Widerspruch bedroht sind: Der Ausfall der Gültigkeit gefährdet z.B. den Zusammenhalt der Eigenschaften und im Anschluss daran den der Essenzen, weil das Kollabieren des Satzes vom Widerspruch solch eine Konstellation nach sich ziehen würde, dass der Inhalt an sich selbst einer Eigenschaft annulliert würde; da jedoch Eigenschaften und Essenzen existieren ${ }^{11}$, muss der Satz vom Widerspruch gültig bleiben.

\footnotetext{
${ }^{7}$ Siehe z.B. Metaphysica Gamma 4, 1006a28-b34.

${ }^{8}$ Siehe z.B. Metaphysica Gamma 4, 1007a20-33.

${ }^{9}$ Siehe z.B. Metaphysica Gamma 4, 1007a33-b18.

${ }^{10}$ Siehe z.B. Metaphysica Gamma 4, 1007b18-1008a2.

${ }^{11}$ Mit Bezug darauf scheint es mir, dass bei Aristoteles die Existenz von Eigenschaften und im Anschluss daran die Existenz von Essenzen ein unbestrittenes und unbestreitbares Thema ist: Aristoteles vermittelt mir den Eindruck - wie ich im Laufe dieser Studie nachzuweisen und zu verdeutlichen versuchen werde -, dass er das Vorhandensein in der Realität von Eigenschaften und von Essenzen nie in Abrede stellen will. Seiner Einschätzung nach liegen in der Realität Eigenschaften vor, und zwar in dem Sinne, dass diese Eigenschaften in der Realität verwurzelt sind oder, anders gesagt, dass sie die Realität selbst ausmachen; diese Eigenschaften wirken als Essenzen von bestimmten Einzelentitäten, da sie diese selben Einzelentitäten ontologisch konstituieren; eine Essenz zu sein, ist für eine Eigenschaft die Konsequenz der Funktion, welche sie im Verhältnis zu einer Einzelentität ausübt: Diese Funktion besteht darin, dass sie die ontologische Konstitution dieser Einzelentität ist; die konstitutive Eigenschaft durchwirkt die ihr entsprechende Einzelentität.
} 
Journal of Ancient Philosophy Vol. V 2011 Issue 2

Aristoteles konstruiert seine Verteidigung des Satzes vom Widerspruch auf der Basis der Grundkomponenten der Realität; er verwendet dazu z.B. die Eigenschaftsinhalte, welche alle im Falle des Verfalls des Satzes vom Widerspruch verschwinden würden; er stützt sich zudem auf die Konstitution der Einzelentitäten, welche im Falle des Verfalls des Satzes vom Widerspruch kollabieren würden. Er bleibt nicht auf der Ebene der akzidentiellen Prädikation und der Zuweisung von akzidentiellen Merkmalen; er konzentriert sich nicht auf rein akzidentielle Verhältnisse zwischen Einzelentitäten und Eigenschaften, um die Gültigkeit des Satzes vom Widerspruch zu verteidigen, da nicht einfach und nicht nur akzidentielle Verhältnisse vom Fall des Satzes bedroht sind. Er sucht und verwendet zur Verteidigung des Satzes vom Widerspruch die Bestandteile der Realität. Aristoteles will meiner Ansicht nach zeigen, dass die Grundstruktur der Realität zusammenfallen würde, wenn der Satz vom Widerspruch nicht mehr gültig wäre: Denn Eigenschaften und Konstitutionen von Einzelentitäten wären in diesem Falle nicht mehr möglich ${ }^{12}$. Man soll sich meiner Meinung nach die Grundstrukturen der Realität vor Augen halten, um die Strategie des Aristoteles zu verfolgen: Denn ebendiese Grundstrukturen wären ohne den Satz vom Widerspruch nicht (mehr) möglich. Durch das bestimmte Manöver, welches die Konsequenzen des Zusammenfalles des Satzes vom Widerspruch illustriert, wird der Gegner des Satzes vom Widerspruch in die Enge getrieben: Denn der Gegner muss bestimmte Realitätsbestandteile wie die Eigenschaftsinhalte und die wesentlichen Konstitutionen der Einzelentitäten gezwungenermaßen ablehnen, wenn er seiner Einstellung gegen die Gültigkeit des Satzes vom Widerspruch treu bleiben will.

Ein fester Punkt der aristotelischen Meditation ist meiner Einschätzung nach die Tatsache, dass sich die Realität aus Eigenschaften zusammensetzt: Die Eigenschaften sind sozusagen in der Realität eingeschrieben. Das Gefüge der Realität, welches vom Ausfall des Satzes vom Widerspruch bedroht wird, welches, mit anderen Worten, vom Zerfall des Satzes vom Widerspruch betroffen wird - wie eben die Existenz von Eigenschaften und Essenzen ein Beispiel für ein gefährdetes Gefüge bildet -, macht

\footnotetext{
${ }^{12}$ D.h. hier ist nicht von akzidentiellen Verhältnissen die Rede, die nicht mehr möglich wären, falls der Satz vom Widerspruch nicht mehr gültig wäre; es bricht alles zusammen, falls der Satz vom Widerspruch zusammenfällt.
} 
Journal of Ancient Philosophy Vol. V 2011 Issue 2

wegen und dank der eigenen Unabdingbarkeit die Basis der Verteidigung des Satzes vom Widerspruch aus: Eigenschaften und Essenzen existieren; genau wegen der Unentbehrlichkeit dieses Gefüges muss der Satz vom Widerspruch seine Gültigkeit behalten; das Gefüge der Eigenschaften und Essenzen bildet nämlich gleichzeitig die Realitätsstruktur, welche vom Fall des Satzes vom Widerspruch bedroht wird, und das Instrument, welches zur Verteidigung des Satzes vom Widerspruch verwendet wird.

Aristoteles entwickelt zur Erarbeitung der Reaktion auf den Angriff gegen den Satz vom Widerspruch ein groß angelegtes Verteidigungsmanöver, welches sich auf die zentralen Aspekte seiner eigenen Ontologie zurückbesinnt. Die Inhalte, welche von Aristoteles in den Kapiteln Metaphysica Gamma 4, 5 und $6^{13}$ dargelegt werden, in

${ }^{13}$ Die in dieser Arbeit zitierten Texte wurden von mir übersetzt, nachdem ich folgende Übersetzungen hinzugezogen hatte: für die Categoriae die Übersetzung von K. Oehler (Aristoteles, Kategorien. Übersetzt und erläutert von Klaus Oehler. Zweite, durchgesehene Auflage, Akademie-Verlag, Berlin 1986); für die Schrift „De Interpretatione“ die Übersetzung von E. Rolfes (Aristoteles, De Interpretatione, übersetzt von E. Rolfes, Felix Meiner Verlag, Hamburg 1995), die Übersetzung von H. Weidemann (Aristoteles, Peri hermeneias. Übersetzt und erläutert von H. Weidemann. Zweite, veränderte Auflage, Akademie Verlag, Berlin 2002), und die Übersetzung von H. G. Zekl (Aristoteles, Kategorien Hermeneutik oder vom sprachlichen Ausdruck (De interpretatione). Beigegeben sind: Porphyrios, Einführung in die Kategorien des Aristoteles (Isagoge); Pseudo-Aristoteles: Einteilungen (Divisiones); PseudoPlaton: Begriffsbestimmungen (Definitiones). Herausgegeben, übersetzt, mit Einleitungen und Anmerkungen versehen von Hans Günther Zekl, Felix Meiner Verlag, Hamburg 1998); für die Metaphysica die Übersetzung von H. Bonitz - i) in der Bearbeitung von H. Seidl (Aristoteles, Metaphysik, in der Übersetzung von H. Bonitz, neu bearbeitet mit Einleitung und Kommentar herausgegeben von H. Seidl, griechischer Text in der Edition von W. Christ, 2 Bde., zweite, verbesserte Auflage, Felix Meiner Verlag, Hamburg 1982; dritte, verbesserte Auflage, Felix Meiner Verlag, Hamburg 1989 (erster Halbband, Bücher I-VI) - Hamburg 1991 (zweiter Halbband, Bücher VII-XIV)) und ii) in der neuen Ausgabe von U. Wolf, welche sich auf die Bearbeitung von H. Carvallo und E. Grassi stützt (Aristoteles, Metaphysik, in der Übersetzung von $\mathrm{H}$. Bonitz, mit Gliederungen, Registern und Bibliographie herausgegeben von H. Carvallo und E. Grassi, Rowohlt, Reinbek bei Hamburg 1966; auf der Grundlage der Bearbeitung von H. Carvallo und E. Grassi neu herausgegeben von U. Wolf, Rowohlt Taschenbuch Verlag, Reinbek bei Hamburg 1994), die Übersetzung von H. G. Zekl (Aristoteles, Metaphysik, übersetzt, mit einer Einleitung und Anmerkungen versehen von H. G. Zekl, Königshausen \& Neumann, Würzburg 2003) und die Übersetzung von T. A. Szlezák (Aristoteles, Metaphysik. Übersetzt und eingeleitet von T. A. Szlezák, Akademie Verlag, Berlin 2003); für die Schrift „De Anima“ die Übersetzung von W. Theiler (Aristoteles, Über die Seele. Übersetzt von Willy Theiler. Zweite, durchgesehene Auflage, Akademie-Verlag, Berlin 1966), die Übersetzung von O. Gigon (Aristoteles, Vom Himmel. Von der Seele. Von der Dichtkunst. Übersetzt, herausgegeben und für die vorliegende Ausgabe mit einer neuen Vorbemerkung versehen von O. Gigon, Deutscher Taschenbuch Verlag, München 1987), und die Übersetzung von H. Seidl (der allerdings die Übersetzung von W. Theiler zu Rate gezogen hat: Aristoteles, Über die Seele. Mit Einleitung, Übersetzung (nach W. Theiler) und Kommentar herausgegeben von 
Journal of Ancient Philosophy Vol. V 2011 Issue 2

denen die Gültigkeit des Satzes vom Widerspruch verteidigt wird, hängen tatsächlich wenn sie unter die Lupe genommen werden - mit zentralen Themen der Ontologie und der Wahrnehmungslehre des Aristoteles zusammen: Alles, was den Satz vom Widerspruch betrifft, ist zentrales Thema in der aristotelischen Spekulation; all die Argumente zugunsten des Satzes vom Widerspruch bilden sozusagen „Asse“ der aristotelischen Meditation. Die Leserinnen und Leser werden in diesen Kapiteln mit Hauptthesen der aristotelischen Philosophie konfrontiert; es liegt sozusagen kein Argument „zweiter Wahl“ vor; die Instrumente und der ontologische Apparat, welche zur Verteidigung der Satzes angewendet werden, erweisen sich, bei Lichte besehen, immer als Argumente erster Wahl. Da das Prinzip aller Prinzipien, d.h. der Satz vom Widerspruch, Gefahr läuft, in Abrede gestellt zu werden, muss dementsprechend zu dessen Verteidigung auf die Basis der Ontologie selbst, auf die Wurzeln der Realitätsstruktur, auf die fundamentalsten Dinge zurückgegriffen werden ${ }^{14}$ : Denn solche Hauptthemen der aristotelischen Ontologie wie

- das Gefüge der Eigenschaften und der Essenzen,

- der Zusammenhalt des kategorialen Systems,

- die Existenz der Pluralität von den dem Wesen nach unterscheidbaren Entitäten,

- der Begriff von Form,

Horst Seidl. Griechischer Text in der Edition von Wilhelm Biehl u. Otto Apel, Felix Meiner Verlag, Hamburg 1995); für die Topica die Übersetzung von E. Rolfes (Aristoteles, Topik, übersetzt von E. Rolfes, Felix Meiner Verlag, Hamburg 1995). Ich übernehme selbstverständlich die ganze Verantwortung für die Übersetzungen, die ich in dieser Arbeit zum Ausdruck bringe, und empfehle zugleich, einen Vergleich von meinen Übersetzungsvorschlägen mit anderen Übersetzungen durchzuführen, um ein detaillierteres Bild der Übersetzungsmöglichkeiten zu bekommen.

${ }^{14}$ Mit anderen Worten: Würde der Satz vom Widerspruch zusammenfallen, so würde die Realität selbst zusammenfallen. Auf dass gezeigt werden kann, dass der Satz vom Widerspruch seine Gültigkeit behalten muss, muss auf die Wurzeln und auf die Existenz-MöglichkeitBedingungen der Realität selbst zurückgegriffen werden; wenn die ganze Realität wegen der Bedrohung des Satzes vom Widerspruch auf dem Spiel steht, sollen die Wurzeln der Realität berücksichtigt werden, auf dass der Satz vom Widerspruch verteidigt werden kann, da die ganze Realität, wie es sich zeigen wird, vom Satz vom Widerspruch abhängt). Aus diesem Punkt resultiert auch, dass die Strategie zur Verteidigung des Satzes vom Widerspruch auch eine Analyse der Grundfesten der Ontologie ist: Da nämlich der Satz vom Widerspruch die Basis der Realität ist, ist die Strategie zur Verteidigung des Satzes vom Widerspruch auch eine Analyse der Basis der Realität. Denn durch die Analyse des Satzes vom Widerspruch und dessen Verbindungen mit den Grundkomponenten der Realität werden die Grundkomponenten der Realität unter die Lupe genommen. 
Journal of Ancient Philosophy Vol. V 2011 Issue 2

- die Interpretation der Inhalte der Wahrnehmung und so weiter, welche die Instrumente zur Verteidigung der Gültigkeit des Satzes vom Widerspruch ${ }^{15}$ bilden, entsprechen der Basis der aristotelischen Meditation über die Struktur der Realität und über das Verhältnis zwischen wahrnehmendem Subjekt und Realität: Man befindet sich hier wirklich im Herzen der aristotelischen Ontologie.

Bevor ich einige Punkte des aristotelischen Manövers analysiere, möchte ich zuerst einige Definitionen darlegen, welche dann zur Klarheit meiner darauf folgenden Auslegung der Verteidigungsstrategie dienlich sein könnten. Da der nun folgende Paragraph ausschließlich einige generelle Erklärungen liefert, kann er, falls das Interesse der Leserinnen und Leser ausschließlich der Interpretation der Aspekte von Metaphysica Gamma 4, welche ich hier in Betracht ziehen werde, gelten sollte, übersprungen werden. Die Inhalte dieses Paragraphen können allerdings auch im Laufe der Lektüre meiner Arbeit konsultiert werden.

\section{b) Grundvoraussetzungen, Definitionen, Erklärungen und Stellungnahmen}

Das Ziel dieses Paragraphen ist es, mein Verwenden von bestimmten Konzepten zu erklären und zu verdeutlichen, so dass so wenige Missverständnisse wie möglich, die meine Interpretation verursachen könnte, entstehen ${ }^{16}$. Die in diesem Paragraphen enthaltenen Definitionen können eventuell auch eine Art Synthese von einigen

15 In diesem Entwurf werde ich mich auf einige Elemente des Verteidigungsmanövers einschränken müssen. Im Besonderen werde ich denjenigen Argumenten meine Aufmerksamkeit widmen, welche die Gefahr und die Folgen des Zusammenfalles von Eigenschaften und Essenzen betreffen; weitere Argumente werde ich in künftigen Analysen behandeln. Ich verweise in dieser Hinsicht für die Analyse weiterer Argumente zur Verteidigung des Satzes vom Widerspruch auf eine zusätzliche Studie zurück, an welcher ich schon arbeite, und welche auf bestimmte Argumente von Metaphysica Gamma 4 und Gamma 5 konzentriert sein wird.

${ }^{16}$ Es erweist sich in diesem Zusammenhang als angezeigt, zu spezifizieren, dass diese Konzepte meiner Ansicht nach Aspekte der aristotelischen Ontologie wiedergeben möchten; sie sind nämlich nicht meine persönliche Erfindung (oder zumindest möchten sie nicht meine persönliche Erfindung sein), sondern sie können - meiner Ansicht nach - an bestimmten Textstellen des Aristoteles gefunden werden oder von bestimmten Textstellen des Aristoteles bestätigt werden. 
Journal of Ancient Philosophy Vol. V 2011 Issue 2

Aspekten meiner Interpretation manch eines Elementes der aristotelischen Ontologie liefern.

1) Die Grundvoraussetzungen, die Aristoteles meiner Meinung nach im Laufe der Verteidigung des Satzes vom Widerspruch verwendet, sind die Folgenden:

a. Es existieren Eigenschaften.

b. Die Eigenschaften sind in der Realität verwurzelt, d.h. sie sind nicht reine Klassifikationen des Intellektes, der auf die Realität seine eigenen Schemata anwendet; die Eigenschaften sind ein tatsächlicher Bestandteil der Realität.

c. Die Einzelentitäten sind konkretisierte Eigenschaften; die lebendigen Einzelentitäten sind Eigenschaftsinhalte, welche sich selbst in den Einzelentitäten realisieren (der Inhalt der Eigenschaft „Mensch-Sein“, welcher mit der Seele des Menschen koinzidiert, realisiert sich selbst im individuellen Menschen).

2) Das altgriechische Wort „oư mit dem Ausdruck „Substanz“ wiedergegeben.

3) Der altgriechische Ausdruck ,, $\tau$ ò $\tau$ í $\tilde{\eta} v$ ع $\tilde{\imath} v \alpha \iota$ “ wird von mir in dieser Studie mit dem Wort „Wesen“ wiedergegeben.

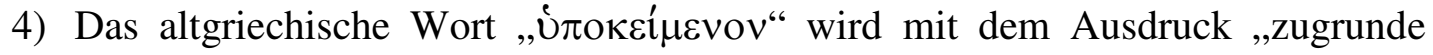
Liegendes“ wiedergegeben. Die Vorkommnisse des Ausdrucks „zugrunde Liegendes“ gelten als Bezug auf das logische Subjekt einer Aussage; ,zugrunde Liegendes" ist zudem Ausdruck der Funktion des ontologischen Subjekts, welche die Substanz im Verhältnis zu den Attributen ausübt (z.B. übt die Substanz „Mensch“ im Verhältnis zum Attribut „gebildet“ die Funktion des zugrunde Liegenden aus, wenn ein Mensch gebildet ist; die Substanz ist die ontologische Basis für das Attribut „gebildet“).

5) Unter „Entität“ wird in dieser Arbeit ausschließlich eine Entität verstanden, welche der äußeren, tatsächlichen, somit nicht lediglich der subjektiven Realität angehört; jegliche Entität, welche dieser Definition entspricht, ist ein Element der tatsächlichen Realität. Die äußere Realität existiert ganz unabhängig davon, ob das lebende Subjekt sie denkt, sie nicht denkt, sie erkennt oder sie nicht 
Journal of Ancient Philosophy Vol. V 2011 Issue 2

erkennt; die äußere Realität ist vom wahrnehmenden, denkenden und erkennenden Subjekt unabhängig. Das Subjekt findet die Inhalte der Realität; es erfindet sie nicht.

6) Unter „Eigenschaft“ wird in diesem Text ausschließlich die tatsächliche Beschaffenheit einer Entität verstanden (d.h. es werden unter Eigenschaften ausschließlich die realen Eigenschaften verstanden). Als Beispiele für reale Eigenschaften können die biologischen Eigenschaften angeführt werden: Die Eigenschaft „Mensch-Sein“ korrespondiert mit einer realen Eigenschaft, da „Mensch-Sein“ eine biologische und infolgedessen eine reale Beschaffenheit bildet; „Nicht-Mensch-Sein“ stellt hingegen ein vom Intellekt erfundenes Charakteristikum dar und wird folglich nicht als eine reale Eigenschaft eingeordnet. Unter Eigenschaft wird deswegen in dieser Arbeit ausschließlich eine reale Eigenschaft ${ }^{17}$ verstanden.

7) Jede Eigenschaft hat an sich selbst einen bestimmten Inhalt, welcher von den Konkretisierungen jeglicher Eigenschaft aktuiert, bewerkstelligt, realisiert wird. Die Eigenschaft „Mensch-Sein“, welche die Seele selbst des Menschen ist, d.h. welche mit der Seele des Menschen äquivalent ist, ist z.B. ein Programm von Anlagen, Fähigkeiten, Dispositionen, das sich im Leben des Organismus „Mensch“ realisiert; die Seele des Menschen ist ein sich selbst realisierendes und aktualisierendes Programm ${ }^{18}$. Die Eigenschaften existieren als Programme

\footnotetext{
${ }^{17}$ Der Unterschied zwischen realer Eigenschaft und erfundenem Charakteristikum ist meiner Ansicht nach mit der aristotelischen Differenzierung zu verbinden, welche zwischen Namen und unbestimmtem Namen vorliegt (siehe dazu De Interpretatione 2, 16a19-b5, insbesondere

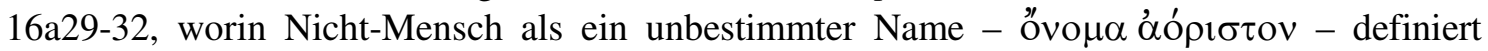
wird; zu diesem Thema kann auch die Stelle De Interpretatione 10, 19b7-10 hinzugezogen werden). Einem echten gemeinen Namen entspricht eine reale Eigenschaft; einem unbestimmten Namen entspricht hingegen keine reale Eigenschaft. Äußerst interessante Analysen dieser Themen bietet meiner Ansicht nach die Studie von T. Irwin, „Aristotle's concept of signification“ an (enthalten in: „Language and Logos. Studies in ancient Greek philosophy presented to G. E. L. Owen“, edited by M. Schofield and M. C. Nussbaum, Cambridge University Press, Cambridge 1982, Seiten 241-266).

${ }^{18}$ Es könnte meiner Meinung nach gesagt werden, dass die Seele ein Eigenschaftsinhalt ist, welcher dazu fähig ist, sich selbst zu realisieren. Die Seele eines Menschen ist gemäß den Beteuerungen des Aristoteles, die in De Anima II 1, 412a1-22, II 1, 412b10-22, II 2, 414a12-28, II 4, 415b8-20 zur Entfaltung gebracht werden, das Wesen des Menschen: Die Essenz von einem Menschen ist nämlich seine Seele, welche meiner Meinung nach von Aristoteles als ein
} 
Journal of Ancient Philosophy Vol. V 2011 Issue 2

für die Realisierung in den Einzelentitäten; sie sind nicht Selbstrealisierungen: Die Eigenschaft „Mensch-Sein“ ist kein Mensch; die Eigenschaft „Rot-Sein“ ist ihrerseits nicht $\operatorname{rot}^{19}$. Anders gesagt, liegt keine Eigenschaft „Mensch-Sein“ vor, welche unabhängig von einem bestimmten Menschen lebt: Wir haben nicht hier

sich selbst realisierendes Programm angesehen wird; die Seele ist eine Kraft, welche ihren eigenen Inhalt in der Gesamtheit des Individuums realisiert; siehe diesbezüglich z.B. die folgende Stelle De Anima II 1, 412b10-17: «Allgemein ist nun also dargelegt worden, was die

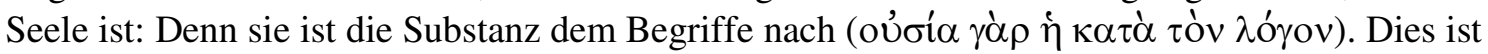

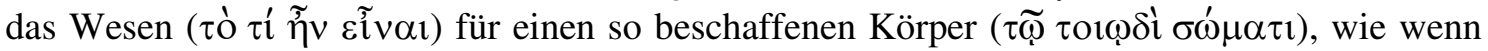
eines von den Werkzeugen ein natürlicher Körper wäre, wie zum Beispiel ein Beil; denn das

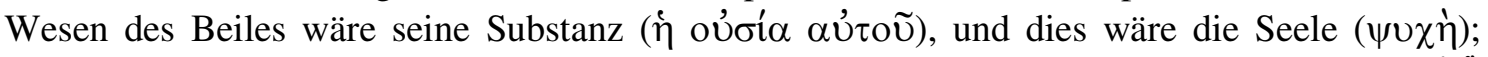
wenn diese getrennt würde, wäre es kein Beil mehr, es sei denn nur dem Namen nach ( $\alpha \lambda \lambda \lambda^{\prime} \hat{\eta}$ ó $\mu \omega v \cup ́ \mu \omega \varsigma)$; nun aber ist es ein Beil. Denn nicht von einem so beschaffenen Körper ist die

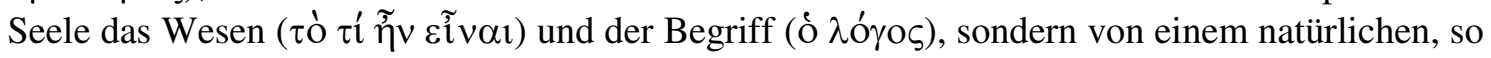
beschaffenen Körper, welcher das Prinzip der Bewegung und Ruhe in sich besitzt.» Da die Seele die Essenz des Menschen ist, würde der Zusammenfall des Satzes vom Widerspruch solch eine Lage mit sich bringen, dass, da jede beseelte Einzelentität, wie z.B. ein Mensch, wegen des Kollabierens des Satzes vom Widerspruch nicht mehr die eigene Essenz wäre (denn keine Essenz mehr würde existieren), diese bestimmte Einzelentität nicht mehr die eigene, innere, dirigierende Kraft sein könnte: Ein Mensch würde nicht mehr er selbst sein. Für weitere Bemerkungen über die Art und Weise, wie ich die Rolle der Seele bei Aristoteles interpretiere, verweise ich auf meinen Aufsatz „Die aristotelische Substanz als Wendepunkt in der Ontologie der Antike“ (enthalten in: „Literaturwissenschaft als Begriffsgeschichte“ (Archiv für Begriffsgeschichte, Sonderheft 8), herausgegeben von Christoph Strosetzki, Felix Meiner Verlag, Hamburg 2010, Seiten 161-172).

${ }^{19}$ Aristoteles geht nicht von einer an sich selbst leeren Realität aus, welche vom erkennenden Subjekt sozusagen konstruiert würde. Die Eigenschaften sind da, und mit ihnen sind bestimmte Inhalte für die Eigenschaften vorhanden. Wenn Aristoteles innerhalb der Verteidigung des Satzes vom Widerspruch zwecks derselben Verteidigung mit der Annahme von "Mensch = Zweifüßiges Tier" ansetzt (siehe dazu Metaphysica Gamma 4, 1006a31-32), hat er sich selbst und uns schon in eine Realität versetzt, welche in und aus Eigenschaften besteht. Aristoteles besagt nämlich, dass etwas wie Mensch-Sein mit dessen determiniertem Inhalt in der Realität anwesend ist. Ohne die Eigenschaftsinhalte, die er als stabil und bestimmt analysiert und erachtet, könnte er meiner Meinung nach nicht zur Verteidigung des Satzes vom Widerspruch gelangen (Aristoteles hätte z.B. nicht erfundene Eigenschaften in Betracht ziehen können, da diese nämlichen erfundenen Eigenschaften ihm nicht ermöglicht hätten, seinen Gegner direkt mit der Realität auseinandersetzen zu lassen). Aristoteles muss unbedingt einen tatsächlichen und effektiven Stutzpunkt finden: Ein erfundenes Charakteristikum, von welchem nicht klar sein kann, welche Inhalte es tatsächlich besitzt, würde sich immer den Kritiken ausgeliefert finden. Eine Eigenschaft, welche einen rigoros definierten Inhalt hat, ist hingegen ein Element der Realität, das nicht in Abrede gestellt werden kann (es sei denn, dass man jede Eigenschaft negieren will). 
Journal of Ancient Philosophy Vol. V 2011 Issue 2

die Eigenschaft „Mensch-Sein“ und dort den individuellen Menschen ${ }^{20}$, als ob diese beiden Entitäten zwar auf demselben Stockwerk der Realität, jedoch voneinander getrennt existieren könnten; die Eigenschaften sind ausschließlich in den Einzelentitäten wirksam: Sie existieren nicht getrennt von den Einzelentitäten.

8) Mit „Einzelentität“ ist die Konkretisierung oder, anders gesagt, die Instantiation $^{21}$ einer realen Eigenschaft gemeint: Der einzelne Mensch stellt die Konkretisierung oder, anders gesagt, die Instantiation der realen Eigenschaft „Mensch-Sein“ dar, welche ihrerseits einer substantialen Art entspricht und diese Art inhaltlich (d.h., was die Eigenschaften anbelangt, welche diese bestimmte Art von den anderen Arten abgrenzen) determiniert; das einzelne Tier bildet die Konkretisierung der Eigenschaft „Tier-Sein“, welche einer substantialen Gattung entspricht und diese Gattung inhaltlich determiniert. Die Einzelentität an sich selbst ist folglich kein einfacher Platzhalter für Eigenschaften oder für die Abfolge von Erscheinungen von Eigenschaften, der einerseits an sich selbst leer wäre oder zu den unterschiedlichen Eigenschaften indifferent wäre, und der andrerseits Eigenschaften in sich selbst von Mal zu Mal aufnähme. Im Gegensatz dazu ist jegliche Einzelentität an sich selbst als eine konkretisierte Eigenschaft anzusehen, denn sie kommt in die Realität eben als eine konkretisierte Eigenschaft hervor; jede Einzelentität hat selbstverständlich akzidentielle Eigenschaften, die aufscheinen und verschwinden können; sie ist jedoch an sich selbst etwas. Im Besonderen ist jede lebende Einzelentität an sich selbst eine konkretisierte Eigenschaft, welche die Funktion ihres Lebens determiniert, verwaltet und steuert. Der einzelne, individuelle, bestimmte Mensch ist die konkretisierte Eigenschaft „MenschSein“: Auf diese Art und Weise kommt er zustande. Das individuelle Rote, d.h. die individuelle Konkretisierung der Farbe „Rot“, welche dem Bereich der

\footnotetext{
${ }^{20} \mathrm{Zu}$ diesem Thema siehe Kung, ,Aristotle on Thises, Suches and the Third Man Argument“ (enthalten in: „Phronesis“, XXVI, 3 (1981), Seiten 207-247).

${ }^{21}$ Anstelle des Ausdrucks „Instantiation“ können auch die Ausdrücke „Exemplifizierung“ oder „Instantiierung“ gebraucht werden; all diese Ausdrücke sind für mich miteinander äquivalent.
} 
lebenden Entitäten nicht angehört, ist die konkretisierte Eigenschaft „Rot-Sein“ und so weiter. Jedwede Einzelentität, ganz gleich, ob sie eine lebende oder eine nicht-lebende Einzelentität ist, ist daher aus ihrer eigenen ontologischen Verfassung heraus eine konkretisierte Eigenschaft.

9) Sowohl Eigenschaften wie auch Einzelentitäten sind reale Entitäten ${ }^{22}$. Meiner Ansicht nach plädiert Aristoteles für eine Ontologie, welche unter anderem

i. Einzelentitäten als Konkretisierungen von Eigenschaften und

ii. Eigenschaften, die im generellen Sinne, d.h. auf generelle Art und Weise genommen werden,

vorsieht; diese Ontologie wartet uns sozusagen mit zwei Stockwerken auf: Mit dem Stockwerk der Einzelentitäten und mit dem Stockwerk der Eigenschaften ${ }^{23}$. Beide Stockwerke gehören der Realität an; diese Stockwerke sollen jedoch voneinander rigoros getrennt werden, und zwar in dem Sinne, dass keine Entität beiden Stockwerken angehören kann: Denn wenn wir Einzelentitäten vor uns haben, haben wir immer individuelle Entitäten vor uns (der individuelle Mensch ist ein Beispiel für eine Einzelentität). Wenn wir hingegen Eigenschaften vor uns haben, welche im generellen Sinne genommen werden, haben wir einen Dispositionen-Inhalt vor uns, welcher als seinen eigenen Platz in der Realität die Funktion von Potentialität für die Konkretisierung hat: Eine Eigenschaft - im generellen Sinne genommen - bildet jedoch, obwohl sie an sich selbst ausschließlich eine Potentialität ist, eine in der Realität tatsächlich verwurzelte Struktur, da sie zusammen mit den anderen Eigenschaften den Raum der möglichen Sorten von Einzelentitäten zusammenstellt; sie macht mit den anderen Eigenschaften den Raum der möglichen Einzelentitäten aus, und dies in

\footnotetext{
${ }^{22}$ Demzufolge können in dieser Arbeit bald Eigenschaften, bald Einzelentitäten ganz allgemein als Entitäten bezeichnet werden.

${ }^{23}$ Selbstverständlich kann die Ontologie des Aristoteles nicht nur auf die Anwesenheit dieser zwei Stockwerke reduziert werden; jedoch sind diese zwei Stockwerke meines Erachtens unentbehrliche Komponenten der Konstitution der aristotelischen Ontologie. Man könnte in diesem Kontext von einer Zwei-Reviere-Ontologie sprechen, welche als ihre eigenen Bestandteile die zwei miteinander inkompatiblen Etagen einerseits der Einzelentitäten und andererseits der generell genommenen Eigenschaften hat.
} 
Journal of Ancient Philosophy Vol. V 2011 Issue 2

dem Sinne, dass die Sorten, in welchen die Einzelentitäten zum Vorschein kommen können (Menschen, Pferde, Bäume und so weiter), schon im Voraus gegeben sind.

Falls eine Eigenschaft instantiiert wird, wechselt sie sozusagen die Etage von der Etage der generell genommenen Entitäten zur Etage der Einzelentitäten, indem sie in einer Einzelentität operativ wird und wirkt; sie ist nicht mehr etwas, das generell genommen wird und das nur potentiell tätig ist; sie ist, mit anderen Worten, nicht mehr ein nicht wirkender, ein inaktiver Dispositionen-Inhalt, sondern sie wird zu einem Faktor, der in einer Einzelentität aktuiert wird ${ }^{24}$. Eine Eigenschaft konstituiert ihre eigenen Konkretisierungen, sie macht ihre eigenen Konkretisierungen in dem Sinne aus, dass diese Konkretisierungen eben konkretisierte Eigenschaften sind: Infolgedessen können die Konkretisierungen nicht von der Eigenschaft losgelöst oder getrennt werden.

10) Eine Essenz ist der Komplex von Eigenschaften, welcher die Einzelentität ausmacht und konstituiert; eine Eigenschaft (oder ein Komplex von Eigenschaften) ist, mit anderen Worten, eine Essenz, falls sie ein bestimmtes

\footnotetext{
${ }^{24}$ Um ein Beispiel davon anzuführen, werde ich die Eigenschaft „Mensch-Sein“ in Erwägung ziehen: Diese Eigenschaft, welche bei Aristoteles allem Anscheine nach, falls sie konkretisiert wird, mit der Seele des Menschen koinzidiert (siehe diesbezüglich z.B. De Anima II 1, 412b1017), existiert im generellen Sinne als der Dispositionen-Inhalt, welcher all die Menschen zu dem macht, was sie ihrer Essenz nach sind. An sich selbst stellt diese Eigenschaft einen Inhalt von Anlagen und Fähigkeiten dar, welcher jeden Menschen qua Menschen aktuiert und dirigiert, falls so etwas wie ein Mensch tatsächlich vorliegt (wenn etwas ein Mensch ist, ist dieses bestimmte Etwas die Eigenschaft „Mensch-Sein“); die Eigenschaft „Mensch-Sein“ ist nämlich eine Potentialität, welche jedoch im tatsächlichen Gefüge und System der biologischen Arten verwurzelt ist, die an sich selbst schon im Voraus gegeben sind. Falls diese Eigenschaft realisiert wird, ist sie nicht mehr ein reiner Dispositionen-Inhalt, sondern sie wird in einem individuellen Menschen tätig, und zwar in dem Sinne, dass sie all die Manifestationen, Fähigkeiten, Anlagen dieses individuellen Menschen organisiert, verwaltet, steuert und dirigiert; aus dem Zustand der generell genommenen Potentialität ist sie durch die Instantiierung zum Zustand der individuellen tätigen Kraft übergegangen. Eine Eigenschaft im generellen Sinne genommen ist eine Komponente der Realität: Sie bildet ein tatsächliches Gerüst der Realität, und zwar in dem Sinne, dass sie eine der möglichen Instantiierungsweisen repräsentiert welche alle im Falle der lebenden Einzelentitäten mit einem bestimmten Lebensprogramm korreliert sind -, in denen die Einzelentitäten zum Vorschein kommen. Denn die biologischen Einzelentitäten werden zwar in der Gestalt von dieser oder jener biologischen Art, aber immerhin in der Gestalt von einer biologischen Art in Erscheinung treten, welche schon im Voraus gegeben ist, und welche zusammen mit den anderen biologischen Arten den Raum der möglichen Realisierungen zusammenstellt.
} 
Journal of Ancient Philosophy Vol. V 2011 Issue 2

Verhältnis mit der Einzelentität hat, welcher sie zukommt: Die Essenz ist die Konsistenz, die ontologische Verfassung, das Konstitutive der Einzelentitäten; eine determinierte Eigenschaft ist die Essenz von einer Einzelentität, falls sie die Konstitution dieser selben Einzelentität bildet: Die Funktion einer Essenz kann dementsprechend als diejenige bestimmte Funktion angesehen und definiert werden, welche von einer Eigenschaft im Falle ausgeübt wird, dass sie die ontologische Verfassung von einer Einzelentität repräsentiert.

Ohne Essenz liegt keine Einzelentität vor, und zwar in dem Sinne, dass jede Einzelentität immer eine Eigenschaft oder ein Komplex von Eigenschaften ist, welcher für die Einzelentität konstitutiv ist. Es liegt demgegenüber keine Einzelentität vor, welche keine Essenz hat; jede Einzelentität ist ein System von Eigenschaften, welches das Programm für diese selbe Einzelentität konstituiert: Mit anderen Worten, bedeutet für eine Einzelentität das Real-Sein, eine Konkretisierung von Etwas zu sein, ein konkretisiertes Etwas zu sein, wobei das „Etwas“ für eine reale Eigenschaft steht. Das Wesen ist infolgedessen die Bedingung für das Real-Sein der Einzelentitäten; ohne Essenz öffnet sich kein Raum für das Real-Sein. Bei den Lebewesen ist das Wesen die Form, die Natur, das Lebensprinzip, der Aktualisierungsfaktor der Einzelentitäten: Das Wesen ist in diesem ontologischen Zusammenhang die im Inneren wirkende Kraft der Individuen; sie ist, mit anderen Worten, das Betriebssystem der lebendigen Einzelentitäten; bei den nicht lebendigen Einzelentitäten ist die Essenz, auf der anderen Seite, der Komplex von Eigenschaften, welcher die Einzelentität inhaltlich bestimmt (die Essenz von der Zahl „3“ ist der Komplex von Eigenschaften, welcher die Zahl „,3“ inhaltlich bestimmt und sie von allen anderen Zahlen unterscheidet) ${ }^{25}$.

\footnotetext{
${ }^{25}$ Eine Essenz, welche für die lebendigen Einzelentitäten gilt, ist eine Eigenschaft, welche in einem bestimmten Verhältnis zu den Einzelentitäten, denen sie zukommt, steht: Sie ist das die Einzelentität Konstituierende, Verfassende, Bildende, Zusammenstellende; sie ist das sich selbst realisierende Programm, welches die Einzelentität durchdringt. Wesen ist Leben; Wesen wirkt! Man könnte diesen Punkt folgendermaßen glossieren: Wesen ist mehr als das, was in der einfachen Definition zum Vorschein kommt. Wenn z.B. Mensch - als Wesen angenommen als zweifüßiges Tier definiert wird, bringt das zweifüßige Tier eigentlich einen ganzen Bereich von Eigenschaften mit sich: Tier heißt, dass die entsprechende Einzelentität eine Seele hat, die
} 
Journal of Ancient Philosophy Vol. V 2011 Issue 2

11) Aristoteles sieht - meiner Meinung nach - eine Welt einerseits von konkretisierten Eigenschaften, welche die Einzelentitäten sind, und andererseits von Eigenschaften, welche die Programme repräsentieren, die in den Einzelentitäten konkretisiert werden, vor sich: Die Welt von Aristoteles ist eine Welt von Eigenschaften, die entweder in den Einzelentitäten wirksam sind oder als Potentialitäten für die Konkretisierung in den Einzelentitäten existieren. Aristoteles bezieht sich darüber hinaus auf Essenzen, da er sich - meiner Meinung nach - eine Welt von Essenzen (oder von Eigenschaften, welche die Rolle von Essenzen ausüben) vor Augen hält, indem er die Einzelentitäten als konkretisierte Eigenschaften ansieht. Realität heißt: Pluralität von potentiell vorliegenden Eigenschaften und von konkretisierten Eigenschaften; ein Mensch, ein Pferd, ein Baum sind die konkretisierten Eigenschaften „Mensch-Sein“, „Pferd-Sein“, „Baum-Sein“. Man soll diesbezüglich meiner Ansicht nach versuchen, sich in die Sichtweise des Aristoteles zu versetzen: Er sieht, wenn er von Menschen, von Pferden, von Bäumen spricht, Einzelentitäten vor sich, welche ihrer Verfassung nach bestimmte konkretisierte Eigenschaften sind; diese Einzelentitäten sind konstitutiv Eigenschaften, so dass sie diese Eigenschaften nicht verlieren können: Denn dies würde bedeuten, dass diese Entitäten sich selbst sozusagen verlören. Der Zusammenbruch des Satzes vom Widerspruch würde mit Bezug darauf bedeuten, dass jegliche Einzelentität sozusagen sich selbst verlieren würde ${ }^{26}$. Es lässt sich daraus ersehen, wie wichtig das Bestehen des Satzes vom Widerspruch ist.

zumindest der Wahrnehmung fähig ist; eine Seele zu haben, heißt, dass eine Einzelentität in sich selbst eine bestimmte wirkende Kraft hat, oder, anders gesagt, dass die Einzelentität eine bestimmte wirkende Kraft ist, die allen Lebensfunktionen vorsteht. Die Lebensfunktionen, welche im Inhalt des jeweils in Betracht gezogenen Wesens selbst enthalten sind, werden vom System „Wesen-Seele“ zur Entfaltung gebracht. Wesen ist bei den lebendigen Einzelentitäten Lebensprinzip und Tätigkeitsprinzip, ist Lebensinhalt und Tätigkeitsinhalt zugleich.

${ }^{26}$ Anders gesagt, ist die Essenz eines Lebewesens (sei es Pflanze oder Tier) die lebende und lebensspendende Konstitution einer Einzelentität; in diesem Sinne lässt sich einsehen, weshalb eine Einzelentität nicht ohne die Essenz sein kann (es sei denn, dass sie stirbt): Die Einzelentität würde sich selbst verlieren, falls sie die Essenz verlöre. Jegliche lebendige Einzelentität kann nicht ohne ihre aktivierende Konstitution, ohne ihre lebende Konstitution existieren. 
Journal of Ancient Philosophy Vol. V 2011 Issue 2

12) Substanz wird von mir als ein mehrwertiges Konzept interpretiert. Substanz kann folgende Werte haben:

a. Gegenstand (z.B. der individuelle Mensch); in diesem Zusammenhang spreche ich von Substanz im Sinne von Gegenstand oder ich spreche von einstelliger Substanz.

b. Form von etwas; in diesem Sinne spreche ich von zweistelliger Substanz (denn es handelt sich um die Substanz von etwas); dieser Wert von Substanz lässt sich weiter artikulieren:

i) Form, Wesen, Gestaltungsprinzip eines nicht lebenden, nicht biologischen, nicht organischen Gegenstandes (z.B. Substanz als die Form eines Hauses), und

ii) Form, Wesen und Natur, d.h. Organisations- und Entwicklungsprinzip eines lebenden Gegenstandes (z.B. Substanz als die Form des individuellen Menschen: In diesem bestimmten Zusammenhang kommt die Substanz ihrerseits der Seele des Menschen gleich).

c. Materie eines wahrnehmbaren Gegenstandes, d.h. materielle Komponente eines aus Materie und Form bestehenden Zusammengesetzten (z.B. die Materie des individuellen Menschen) ${ }^{27}$.

13) Bezüglich meiner Grundauffassungen über die Theorie der Eigenschaften bei Aristoteles ist es für mich verpflichtend zu sagen, dass ich zahlreichen Ansätzen der Interpretation von Michael-Thomas Liske völlig zustimme, die er in seinem Buch „Aristoteles und der aristotelische Essentialismus“ (Verlag Karl Alber Freiburg/München, Freiburg (Breisgau)/München 1985) erarbeitet hat $^{28}$; unter

27 Ich muss mich in diesem Zusammenhang auf die oben ausgeführte Beschreibung einschränken. Für ausführlichere Darlegungen bezüglich meiner Interpretation der aristotelischen Substanz verweise ich auf meine Arbeit „Aspekte der Substanz bei Aristoteles“ (enthalten in: ,Substantia - Sic et Non“, herausgegeben von Gutschmidt H. - Lang-Balestra, A. - Segalerba, G., Ontos Verlag, Frankfurt am Main 2008, Seiten 35-84).

${ }^{28}$ Das Werk von Liske bildet ohne Zweifel ein unentbehrliches Instrument zur Analyse der vielfältigen Aspekte, welche Aristoteles' Essentialismus der Leserin und dem Leser darreicht. Interessante Studien über Aspekte des aristotelischen Essentialismus sind die beiden Arbeiten von B. Brody, „Why Settle for Anything Less than Good Old-Fashioned Aristotelian 
Journal of Ancient Philosophy Vol. V 2011 Issue 2

anderem stimme ich völlig mit der Auffassung von Liske überein, dass der Satz vom Widerspruch ein Prinzip sei, welches die Realität, und damit nicht nur die Sprache betreffe $^{29}$. Für eine Interpretation, die bestimmte Ansichten des Aristoteles auf die Fundierung der modernen Wissenschaft anwenden will, möchte ich die Deutung von Ernst Jonathan Lowe mit besonderer Berücksichtigung seines Buches „The Four-Category Ontology. A Metaphysical Foundation for Natural Science“ (Clarendon Press, Oxford 2006) erwähnen: Der gesamten Strategie dieses Buches ${ }^{30}$ - im Allgemeinen - und dessen Interpretation und Verwendung der Unterteilung der Entitäten, die Aristoteles im zweiten Kapitel der Categoriae ${ }^{31}$ durchführt - im Besonderen - pflichte ich ohne Zweifel bei. Der Auffassung von Terence Irwin, nach welcher die Verteidigung des Satzes vom Widerspruch eine ontologische, nicht nur sprachliche Abwehr sei, schließe ich mich mit Überzeugung und mit Nachdruck $\mathrm{an}^{32}$. Mit einigen Auffassungen, welche Christopher Kirwan in seinem

Essentialism?“ (enthalten in: „Nous“, 7 (1973), Seiten 351-365) und „Identity and Essence“ (Princeton University Press, Princeton (N. J.) 1980). Eine hochspannende Arbeit, die Aristoteles's Erörterung des Satzes vom Widerspruch zum Thema hat, ist Dancys „Sense and contradiction: a study in Aristotle“ (D. Reidel Publishing Company, Dordrecht-Holland / Boston-U.S.A. 1976). Sehr reichhaltig ist die Forschung von R.-P. Hägler, „Kritik des neuen Essentialismus: logisch-philosophische Untersuchungen über Identität, Modalität und Referenz“ (Ferdinand Schöning, Paderborn · München · Wien · Zürich 1994), welche sich auch mit Aspekten des aristotelischen Essentialismus auseinandersetzt. $\mathrm{Zu}$ empfehlen ist auch das Werk von D. Wiggins, „Sameness and Substance, Basil Blackwell, Oxford 1980“ (diese Studie ist auch in einer überarbeiteten Fassung zu lesen: „Sameness and Substance renewed, Cambridge University Press, Cambridge 2001").

${ }^{29}$ Siehe diesbezüglich in „Aristoteles und der aristotelische Essentialismus“ den Paragraphen 4, „Die Bestimmung des schlechthin Wesentlichen als Wesentliches in bezug auf das grundlegende Verstehen ist mit dem Realismus des Aristoteles kompatibel“", Seiten 49-54 (siehe insbesondere Seite 53).

${ }^{30}$ Die Organisation der Ontologie, welche im Buch von Lowe vorgeschlagen wird, sieht die folgende Unterteilung der Entitäten vor (siehe dazu Seite 22):

- Substantial universals (kinds);

- Non-substantial universals (properties/relations);

- Individual substances (objects);

- Property/relation-instances (modes).

${ }^{31}$ Siehe diesbezüglich Categoriae 2, 1a20-1b9.

${ }^{32}$ Siehe diesbezüglich „Aristotle's concept of signification“ (die diesbezüglichen Angaben sind schon erwähnt worden) und „Aristotle’s first principles“, Clarendon Press, Oxford, 1988. 
Journal of Ancient Philosophy Vol. V 2011 Issue 2

Kommentar zum Buch Gamma der Metaphysica („Aristotle, Metaphysics, Books $\Gamma, \Delta$, and E“, Clarendon Press, Oxford 1971; second edition, Clarendon Press, Oxford 1993“) entfaltet hat, bin ich hingegen nicht einverstanden ${ }^{33}$, weil Kirwan meiner Meinung nach die Zentralität der Eigenschaften und der Essenzen im Rahmen der Verteidigungsstrategie des Aristoteles nicht genügend anerkannt hat ${ }^{34}$.

c) Eigenschaften, Essenzen, Konkretisierungen im Kapitel Metaphysica Gamma 4

Ich möchte mich, wie in der Einführung angedeutet, mit einigen Aspekten der gesamten Argumentation beschäftigen, welche der Verteidigung des Satzes vom Widerspruch angehören: Diese Aspekte entsprechen denjenigen Passagen des Buches Gamma der Metaphysica, in welchen die Bezugnahme auf das Wesen ${ }^{35}$ und auf das Verhältnis zwischen Einzelentität und Wesen am stärksten ist; diese Passagen sind im Kapitel Gamma 4 enthalten.

33 Siehe diesbezüglich im Besonderen die Seiten 93-102 von Kirwans Kommentar. Der Kommentar von Kirwan stellt ein unentbehrliches Instrument zur Interpretation von Metaphysica Gamma dar; die Tatsache, dass ich mit einigen Ansichten von Kirwan nicht einverstanden bin, bedeutet selbstverständlich nicht, dass der Kommentar außer Acht gelassen werden darf; ganz im Gegenteil soll der Kommentar sorgfältig analysiert werden, und er verdient jede Bewunderung.

${ }^{34}$ Selbstverständlich lässt sich der Satz vom Widerspruch auch auf der Basis von einfach akzidentiellen Eigenschaften verteidigen: Die Entitäten können nicht eine Eigenschaft und gleichzeitig auch die Negation von dieser Eigenschaft haben, wenn diese Eigenschaft eine nur einfach akzidentielle Eigenschaft ist. Eine Entität kann nicht „f“" und gleichzeitig nicht „f“ sein ganz unabhängig davon, welche Eigenschaft in Betracht gezogen wird (d.h. zum Beispiel ganz unabhängig davon, ob die jeweils in Erwägung gezogene Eigenschaft eine akzidentielle oder eine wesentliche Eigenschaft der Entität bildet, auf welche sie bezogen wird). Der Punkt ist jedoch, dass Aristoteles Instrumente finden will, welche nicht kritisierbar sein können; die akzidentiellen Eigenschaften sind in dieser Hinsicht nicht imstande, nicht kritisierbare Instrumente in Richtung zur Erarbeitung einer wirksamen Verteidigung zu repräsentieren.

${ }^{35}$ Die Textstelle Metaphysica Zeta 4, 1029b13-16 bietet eine Definition des Wesens an: «Und zunächst lasst uns einige Betrachtungen über das Wesen auf begriffliche Art und Weise anstellen, nämlich, dass das Wesen für jede einzelne Entität das ist, was sie an sich selbst gesagt

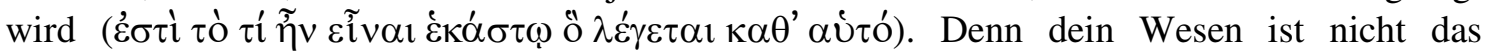

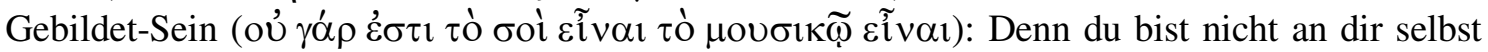

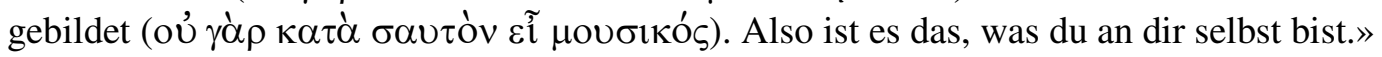


Journal of Ancient Philosophy Vol. V 2011 Issue 2

Um einige Punkte meines Interpretationsansatzes mit einer Formel $\mathrm{zu}$ verdeutlichen, würde ich sagen, dass der rote Faden, welcher sich meiner Ansicht nach durch einige Aspekte der Argumentation des Aristoteles zugunsten der Gültigkeit des Satzes vom Widerspruch hindurchzieht, darin besteht, dass ohne Eigenschaften und im Anschluss daran ohne Essenzen keine Einzelentität vorliegt und vorliegen kann, weil die Möglichkeit selbst jeder beliebigen wesentlichen Identifizierung ${ }^{36}$ einer Einzelentität verschwindet: Ohne Essenz (und generell gesagt ohne Eigenschaften) gehen die ganze Realität und deren Struktur einfach völlig abhanden; nun, eben da die unmittelbare Konsequenz der Ungültigkeit des Satzes vom Widerspruch den Zusammensturz sowohl jeder Eigenschaft als Eigenschaft wie auch der Essenz qua Essenz zeitigen würde und da sich dieses Ergebnis als inakzeptabel erweist, weil die Existenz von den Eigenschaften und von den Essenzen nicht in Abrede gestellt werden kann $^{37}$, muss mithin die Gültigkeit des Satzes selbst sowohl verteidigt wie auch aufrechterhalten werden.

Um nach dieser Präambel die Analyse fortzuführen, möchte ich zuerst die Definition des Satzes vom Widerspruch bekannt geben; der Satz vom Widerspruch wird in Metaphysica Gamma 3, 1005b17-22 in der nachstehenden Weise vorgestellt:

«Dass also ein so beschaffenes Prinzip das sicherste unter allen Prinzipien ist, ist klar

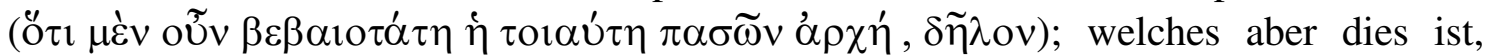
lasst uns danach sagen. Es ist unmöglich, dass dasselbe demselben und in derselben

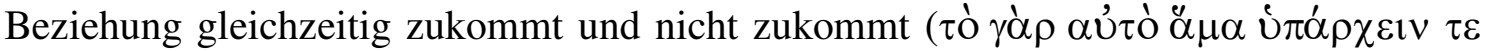

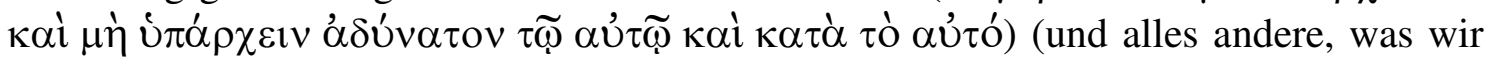
als Spezifizierung hinzufügen, sei gegen die logischen Unannehmlichkeiten hinzugefügt).»

\footnotetext{
${ }^{36}$ Mit dem Terminus „Identifizieren“ und mit all denjenigen Termini, die mit dem Terminus „Identifizieren“, wie z.B. der Terminus „Identifikation“ korreliert sind, meine ich nur, dass durch das Identifizieren von einer Einzelentität die Essenz (oder die Bezeichnung der Essenz) derselben Einzelentität, welcher eine Identität beschieden wird, an den Tag gelegt wird. Das Identifizieren einer Einzelentität heißt infolgedessen nur, ihr Wesen zu manifestieren: Mit anderen Worten, handelt es sich in diesem Zusammenhang, wenn von Identifikation die Rede ist, um eine Identifikation im Wesen (dem Wesen nach); zum Beispiel besteht die Identifizierung von Sokrates in der Feststellung seines Mensch-Seins: Habe ich Sokrates als Mensch eingestuft, so habe ich Sokrates wesentlich identifiziert, da der Inhalt vom Mensch-Sein das Wesen des Sokrates bildet.

${ }^{37}$ Die Eigenschaften sind die Essenzen von den Einzelentitäten, wenn die Einzelentitäten konstitutiv als ihre Konkretisierungen gelten.
} 
Dies ist die generelle Präsentation des Satzes vom Widerspruch. Nun ist es ohne Zweifel wahr, dass die Vorstellung vom Satz vom Widerspruch daran denken lässt, dass sich Aristoteles auf alle Aussagen der Form:

$$
, \text {,a ist } \mathrm{f}^{\prime \prime}
$$

beziehen will, wobei für „f“ irgendeine Eigenschaft gelten kann; in diesem Sinne könnte der Satz vom Widerspruch auf alle apophantischen Aussagen bezogen werden, und dies ganz unabhängig davon, in welchem Verhältnis die Eigenschaft „f“" mit dem zugrunde Liegenden , ,a“ der jeweils in Augenschein genommenen Aussagen steht, d.h. ganz unabhängig davon, ob die in Betracht gezogene Eigenschaft etwas Akzidentielles oder etwas Wesentliches von der Einzelentität zum Ausdruck bringt, welche in der Aussage als zugrunde Liegendes wirkt. Der Satz vom Widerspruch wird in der Tat für alle apophantischen Aussagen, d.h. auch für Aussagen, welche rein akzidentielle Verhältnisse zum Ausdruck bringen, gültig bleiben. Jedoch zieht das folgende Verteidigungsmanöver des Aristoteles nicht jede Eigenschaft und nicht jedes beliebige Verhältnis zwischen Eigenschaft und Einzelentität in Erwägung: D.h. Aristoteles zieht nicht jede beliebige Eigenschaft in Betracht, und stützt sich nicht auf akzidentielle Verhältnisse zwischen Einzelentitäten und Eigenschaften, um den Satz vom Widerspruch zu verteidigen; vielmehr stützt Aristoteles seine Verteidigungsstrategie auf die nachstehenden zwei Punkte:

a) Eine Eigenschaft wie „Mensch-Sein“ hat einen bestimmten Inhalt; sie kann keine Elemente in sich aufnehmen, welche mit diesem Inhalt kontrastieren. Dieser Inhalt ist gegeben und im Voraus gegeben, ist geschlossen und abgeschlossen (ist nämlich vollendet), und dies ganz unabhängig davon, ob wir diesen Inhalt kennen oder nicht kennen.

b) Eine Einzelentität wie „Mensch“ ist aus ihrer eigenen Konstitution heraus eine konkretisierte Eigenschaft, so dass diese selbe Einzelentität von ihrer eigenen Konstitution aus keine Eigenschaft konkretisieren kann, welche mit ihrer Konstitution inkompatibel ist. 
Journal of Ancient Philosophy Vol. V 2011 Issue 2

Eine Linie der Verteidigung des Satzes vom Widerspruch - ich werde diese Linie die ontologische Linie der Verteidigung nennen ${ }^{38}$ - benützt die Existenz von Eigenschaften und die entsprechende Betrachtung der Einzelentitäten als Konkretisierungen von Eigenschaften und als konkretisierte Eigenschaften. Der Gedankengang lässt sich meiner Ansicht nach folgendermaßen darlegen:

- Falls der Satz vom Widerspruch nicht gültig wäre, würden sowohl die Eigenschaften als Dispositionsinhalte für die Einzelentitäten wie auch die Einzelentitäten selbst verschwinden; d.h. der Zusammenbruch des Satzes vom Widerspruch würde das Verschwinden aller Eigenschaften und aller Einzelentitäten mit sich bringen; der Verfall des Satzes vom Widerspruch würde, mit anderen Worten, das Verschwinden der ganzen Pluralität der Entitäten (d.h. sowohl der Einzelentitäten wie auch der Eigenschaften) nach sich ziehen; da jedoch dieses Resultat inakzeptabel ist, muss der Satz vom Widerspruch gültig bleiben. Diese Struktur der Verteidigung stellt sich infolgedessen als eine Reductio ad absurdum heraus.

Die Existenz von Eigenschaften und von den Eigenschaften als Essenzen wird in dieser Hinsicht von Aristoteles als ein so unbestreitbarer, unbezweifelbarer, indiskutabler Punkt erachtet, dass er sich eben der Existenz von Essenzen bedient, um die Gültigkeit des Satzes vom Widerspruch $\mathrm{zu}$ verteidigen. Die Existenz von Eigenschaften ist einfach unbestreitbar; dass Einzelentitäten Essenzen haben, ist ebenfalls unbestreitbar.

Dies ist das, was ich mit ,ontologischer Verteidigung des Satzes vom Widerspruch“ meine, mit anderen Worten: Die Gültigkeit des Satzes vom Widerspruch hängt mit der Struktur der Realität selbst zusammen; falls der Satz vom Widerspruch nicht gilt, geht die Realität selbst zugrunde. Die Verteidigung erweist sich in diesem Sinne als eine solche, welche sich auf die Verfassung der Realität selbst stützt: Der Satz vom Widerspruch ist gleichsam eine Synthese der Verfassung der Realität; ist der Satz vom Widerspruch weg, so ist die Realität weg: Satz vom Widerspruch und Realität sind untrennbar. Der Satz vom Widerspruch bildet in dieser Hinsicht so etwas wie die

${ }^{38}$ Mit der sprachlichen Linie der Verteidigung werde ich mich in diesem Kontext nicht beschäftigen. 
Journal of Ancient Philosophy Vol. V 2011 Issue 2

Grundverfassung, die fundamentale Verfassung der Realität selbst, die Strukturformel der Realität: Ganz unabhängig davon, welche Entität auftritt, ist diese Entität so aufgebaut, dass sie die Erfordernisse des Satzes vom Widerspruch erfüllt und erfüllen muss. Der Bereich des Satzes ist der Bereich des Aufbaus der Realität selbst.

Wie schon angedeutet, gibt Aristoteles zwar eine generelle Formulierung des Satzes vom Widerspruch; wenn jedoch es um die Verteidigung des Satzes vom Widerspruch geht, führt er sozusagen einen Richtungswechsel (sozusagen ein Looping) durch, indem er sich - zumindest bezüglich einiger Argumente - auf die Inhalte der Eigenschaften und auf die Konstitutionen der Einzelentitäten konzentriert. Eine Einzelentität ist, was ihre eigene Struktur betrifft, eine Konkretisierung von einer Eigenschaft, oder, anders gesagt, ist die Einzelentität die konkretisierte Eigenschaft, welche für diese Einzelentität das Wesen darstellt; dies ist die Normalitätsbedingung für jede Entität, wobei in diesem Zusammenhang mit „Normalität““ die Gültigkeit des Satzes vom Widerspruch gemeint ist. Im Besonderen ist die Einzelentität „Mensch“ auf der Ebene ihrer eigenen Konstitution die Konkretisierung der Eigenschaft „MenschSein“ und des entsprechenden Komplexes der Eigenschaften, welcher das Mensch-Sein zusammenstellt. Dieser Punkt wird im Passus Metaphysica Gamma 4, 1006a28-34 zum Ausdruck gebracht:

«Zuerst nun also ist evident, dass ebendies selbst zumindest wahr ist, dass der Name „Sein“ oder der Name „Nicht-Sein“ etwas Bestimmtes bezeichnet ${ }^{39}$ ( $\sigma \eta \mu \alpha i ́ v \varepsilon$ iò

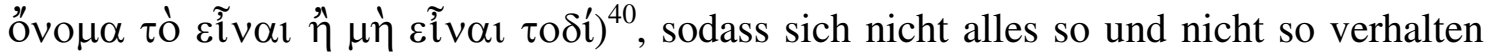

\footnotetext{
${ }^{39}$ Alternative Übersetzung für „,bezeichnet“" ,,bedeutet“.

${ }^{40}$ Auf die Präsenz eines Kontrastes bei den Übersetzungsmöglichkeiten ist meiner Einschätzung nach bezüglich dieser Textstelle, nämlich ,,dass ebendies selbst zumindest wahr ist, dass der Name „Sein“ und der Name „Nicht-Sein“ etwas Bestimmtes bezeichnet“ hinzuweisen. Eine alternative Übersetzung lautet: „dass der Name bedeutet, dieses da zu sein oder nicht zu sein“. Bonitz, Zekl und Szlezák plädieren (wenn auch mit sich voneinander leicht unterscheidenden Formulierungen) für die im Haupttext vorgeschlagene Übersetzungsstrategie; Kirwan befürwortet seinerseits in seinem Kommentar eine Übersetzung, deren englische Version meiner in dieser selben Fußnote soeben vorgeschlagenen alternativen Wiedergabe ähnlich ist (siehe diesbezüglich Seite 10 seines Buches: ,that the name signifies to be or not to be this particular thing"). Ich denke, dass, wenn die Übersetzung angenommen wird, welche ich im Haupttext angenommen habe, Aristoteles zuerst den Unterschied zwischen „Sein“ und „Nicht-Sein“ als Zeichen der Behauptung und der Negation verdeutlichen will, um dann zum Thema der Eigenschaften überzugehen. Wenn hingegen die Variante von Kirwan angenommen wird, setzt sich Aristoteles schon in dieser Aussage mit den Eigenschaften in dem Sinne auseinander, dass die Eigenschaften determinierte Inhalte haben und sie dementsprechend mit der Verneinung
} 


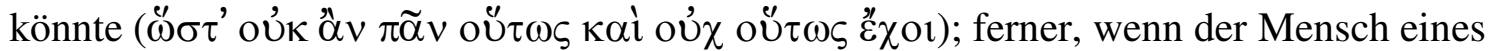

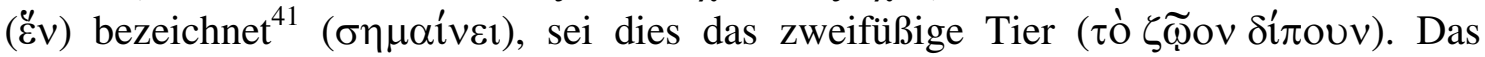

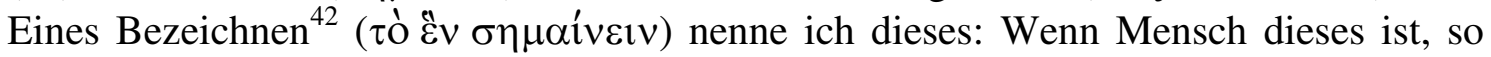

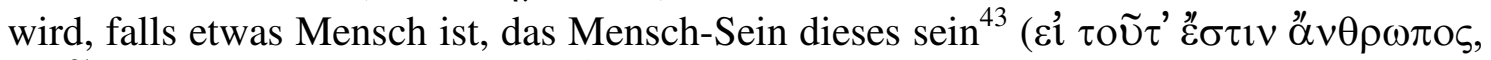

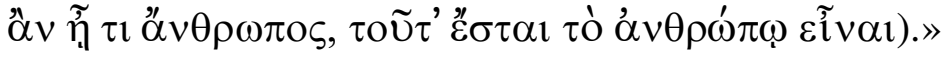

Aristoteles leitet seine Strategie der Verteidigung des Satzes vom Widerspruch in diesem bestimmten Argument auf die folgende Art und Weise ein; er zieht in diesem Falle „Mensch“ in Betracht und definiert, was Mensch ist:

- Mensch ist zweifüßiges Tier; d.h. die Eigenschaft „Mensch-Sein“ besteht im „Zweifüßiges-Tier-Sein“; darin liegt ihr Inhalt.

- Falls eine Einzelentität ein Mensch ist, wird diese Einzelentität das Mensch-Sein sein; die Einzelentität wird nämlich die Eigenschaften, welche das Mensch-Sein bestimmen, konkretisieren. Die in Erwägung gezogene Einzelentität wird infolgedessen von der Eigenschaft „Mensch-Sein“ konstituiert sein; diese Eigenschaft wird ihr Wesen sein.

Am Ende des Zitates werden wir mit zwei ontologischen Etagen konfrontiert, d.h. der Etage der Einzelentitäten (nämlich des bestimmten Menschen) und der Etage der Eigenschaften (des Mensch-Seins) ${ }^{44}$. Es ist in diesem Zusammenhang meiner Ansicht nach bemerkenswert, dass Aristoteles praktisch in derselben Aussage zuerst die Eigenschaft ins Visier nimmt und dann zur Tragweite übergeht, welche die Existenz dieser Eigenschaft für die Einzelentitäten mit sich bringt. Eine Eigenschaft hat z.B.

dieser Inhalte inkompatibel sind. Die Stelle erweist sich nach der zweiten Übersetzungsmöglichkeit als eine Antizipation der folgenden Stelle.

${ }^{41}$ Alternative Übersetzung für „,bezeichnet“: ,,bedeutet“.

${ }^{42}$ Alternative Übersetzung für „Bezeichnen“: „,Bedeuten“.

${ }^{43}$ D.h. dieses wird für ihn das Mensch-Sein sein. Das Mensch-Sein wird für den einzelnen Menschen die Essenz sein, denn ein einzelner Mensch ist das konkretisierte Mensch-Sein; sein Real-Sein ist, eine Konkretisierung von einer bestimmten Eigenschaft (Mensch-Sein) zu sein. Der individuelle Mensch wird daher den Inhalt der Eigenschaft „Mensch-Sein“ konkretisieren.

${ }^{44}$ Es muss meiner Meinung nach immer vor Augen gehalten werden, dass Aristoteles für sein Verteidigungsmanöver beide Bereiche der Entitäten benützt. Es werden in die Argumentation sowohl Eigenschaften wie auch Konkretisierungen von Eigenschaften von Aristoteles eingeführt; beide Bereiche dieser Entitäten werden innerhalb der Argumentation ständig berücksichtigt. Die beiden Bereiche von Entitäten besitzen bestimmte Inhalte und Konstitutionen: Denn jede Eigenschaft hat einen bestimmten Inhalt, während jede Einzelentität eine bestimmte Konstitution hat. 
Journal of Ancient Philosophy Vol. V 2011 Issue 2

diese bestimmten Inhalte; für die Instantiation dieser Eigenschaft bedeutet dementsprechend die Tatsache, dass eine Eigenschaft bestimmte Inhalte hat, dass die Instantiation in sich selbst diese Inhalte konkretisiert, oder, anders gesagt, dass diese Inhalte die Instantiation konstituieren ${ }^{45}$.

Die Voraussetzungen für diesen Gedankengang sind meiner Ansicht nach die Folgenden:

- Es sind Eigenschaften vorhanden, welche die Einzelentitäten determinieren, indem die Einzelentitäten Konkretisierungen von diesen Eigenschaften darstellen: Mithin sind diese Eigenschaften die Essenzen von diesen Einzelentitäten (eine Eigenschaft bildet die Essenz von einer Einzelentität, weil diese Eigenschaft die Einzelentität konstituiert, weil sie nämlich die Einzelentität baut).

- Es sind ein Bezeichnetes oder, anders gesagt, das Bezeichnete oder, noch mal anders gesagt, etwas zu Bezeichnendes vorhanden (d.h. die Eigenschaften sind da); es gibt etwas, das bezeichnet werden kann und bezeichnet wird. Die Operation vom Bezeichnen hat einen tatsächlichen Bezug zur Realität.

- Die Sprache bildet die Struktur der Eigenschaften (= Abteilungen der Realität) ab.

- Das Eines-Bezeichnen ist mit einer Eigenschaft, die einen bestimmten Inhalt mit sich bringt, verknüpft.

Die bestimmte Art und Weise der Interpretation des Bezeichnens der Sprache bei Aristoteles ist, dass das richtige Bezeichnen seitens eines Namens, seitens eines Ausdruckes sozusagen auf eine „Abteilung“ (so möchte ich die Eigenschaften bezeichnen) der Realität Bezug nimmt: Die Ebene der Sprache nimmt auf existierende Eigenschaften Bezug ${ }^{46}$. Der Ansatzpunkt, von welchem Aristoteles in seiner

${ }^{45}$ Z.B. wird der individuelle Mensch unter normalen Bedingungen all die Eigenschaften konkretisieren, welche mit der Eigenschaft „Mensch-Sein“ zusammenhängen oder, anders gesagt, welche in der Eigenschaft „Mensch-Sein“ enthalten sind. Daher wird der einzelne Mensch unter normalen Bedingungen all die bestimmten Fähigkeiten entwickeln, welche mit dem Mensch-Sein verbunden sind.

${ }^{46}$ Es kann diesbezüglich auf die folgende Stelle De Interpretatione 1, 16a3-8 Rekurs gemacht werden, die lautet:«Es sind also die Elemente, welche in der Sprache vorliegen, Zeichen der in

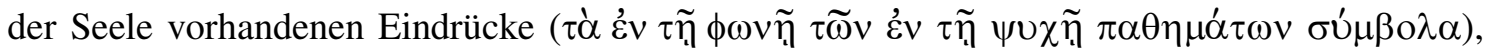
und die geschriebenen Worte sind Zeichen der Elemente, welche in der Sprache vorliegen. Und wie nicht bei allen die geschriebenen Worte dieselben sind, so sind auch die gesprochenen Worte nicht bei allen dieselben; das, von dem als erstem diese ihrerseits Zeichen sind, nämlich 
Journal of Ancient Philosophy Vol. V 2011 Issue 2

Verteidigung des Satzes vom Widerspruch ausgeht, ist daher (meiner Meinung nach), dass Eigenschaften existieren, dass diese Eigenschaften unabhängig vom sprechenden Subjekt existieren und dass diese Eigenschaften als Essenzen von ihren eigenen Konkretisierungen gelten.

Es ist meiner Ansicht nach in diesem Kontext interessant, dass das Konzept von „Eines-Bezeichnen (Eines-Bedeuten)“ auf Eigenschaften bezogen wird. Die Art und Weise, wie sich Aristoteles besonders gegen Ende des zitierten Passus ausdrückt, d.h.:

„Das Eines Bezeichnen ${ }^{47}$ ( $\tau$ ò $\tilde{\varepsilon} \nu$ $\left.\sigma \eta \mu \alpha i ́ v \varepsilon \imath v\right)$ nenne ich dieses: Wenn Mensch dieses ist,

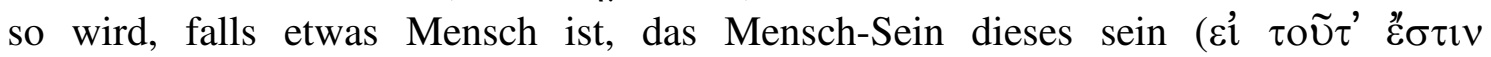

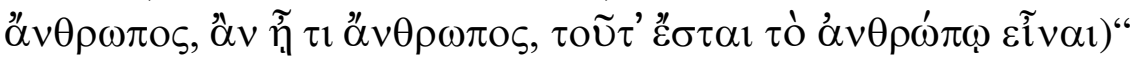

erweckt in mir den Eindruck, dass das Eines-Bezeichnen (Eines-Bedeuten), das in diesem Zusammenhang von „Mensch“ ausgeübt wird, nicht oder nicht nur oder nicht in erster Linie sprachliche Entitäten als seinen eigenen Bezugspunkt hat, sondern von Aristoteles direkt auf den Komplex der Eigenschaften „,zweifüßiges Tier“ gerichtet wird. Die erste Bezugnahme von „Mensch“ betrifft den Komplex der Eigenschaften „Zweifüßiges Tier“. Aristoteles sucht nach Inhalten, welche in der Realität eingeschrieben sind; er lässt allmählich seine Werkzeuge zur Vorbereitung seiner Verteidigungsstrategie in Erscheinung treten.

Aus dem zitierten Passus Metaphysica Gamma 4, 1006a28-34 lässt sich infolgedessen ersehen, dass nach der Ansicht des Aristoteles Eigenschaften und Essenzen existieren; Eigenschaften und Essenzen werden ohne Weiteres in Betracht gezogen: Sie sind einfach vorhanden; dass in der Realität Eigenschaften vorhanden sind, bildet sozusagen den Ansatzpunkt der Strategie. Aristoteles zieht in diesem Zusammenhang zuerst den Inhalt von Mensch-Sein in Betracht (dieser Inhalt besteht im Zweifüßiges-Tier-Sein); dann behauptet er, dass sich diese Eigenschaft als das Wesen

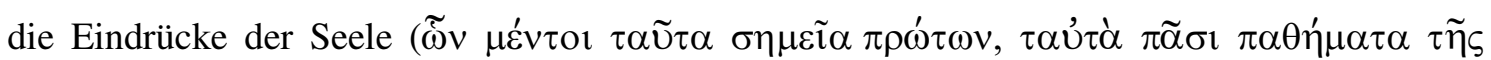
$\psi \cup \chi \tilde{\eta} \varsigma)$, sind jedoch fürwahr bei allen Menschen dieselben, und ebenso sind dieselben die

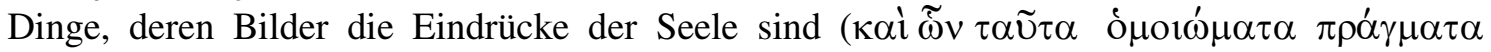
$\eta \eta \delta \eta \tau \alpha \cup ่ \alpha$ ).» Der Punkt, der für mich in diesem Zusammenhang von Interesse ist, besteht in der Tatsache, dass die Eindrücke der Seele auf Dinge der Realität zurückgeführt werden: Es ist nämlich immer die Realität, welche den Auftakt gibt; die Eindrücke der Seele beziehen sich auf Abteilungen der Realität.

${ }^{47}$ Alternative Übersetzung für „Bezeichnen“: „Bedeuten“. 
Journal of Ancient Philosophy Vol. V 2011 Issue 2

von einer Einzelentität erweisen wird, falls diese Einzelentität diese Eigenschaft ist. Dem Gedankengang des Aristoteles liegt, mit anderen Worten, meiner Ansicht nach zugrunde, dass Eigenschaften existieren: Diese werden zwar von den Namen bezeichnet; sie bilden jedoch Inhalte, die für sich selbst bestehen, und die ganz unabhängig vom sprechenden oder denkenden Subjekt existieren. Eigenschaften existieren als Inhalte für die Realisierung in den Einzelentitäten; Einzelentitäten existieren ihrerseits als Instantiationen von bestimmten Eigenschaften ${ }^{48}$.

$\mathrm{Zu}$ bemerken ist diesbezüglich, dass Mensch-Sein für die Einzelentität, welche Mensch ist, nicht eine Eigenschaft ist, die wie z.B. die Eigenschaft „Gebildet-Sein“ ist, welche (in Bezug z.B. auf einen Menschen) erworben oder verloren werden kann: Ein Mensch kann nicht gleichzeitig Mensch und nicht Mensch sein ${ }^{49}$; Mensch-Sein ist für diese Einzelentität konstitutiv; Mensch-Sein ist nämlich seine ontologische Verfassung, seine ontologische Konstitution. Mensch-Sein ist die konstitutive Seinsweise für die individuellen Menschen; ein Mensch kann nicht diese ontologische Verfassung verlieren oder erwerben, weil er Mensch vor jeder Änderung ist; er ist Mensch vor

${ }^{48}$ Es ist diesbezüglich interessant, dass sich Aristoteles allem Anscheine nach nicht darum kümmert, den möglichen Einwand in Betracht zu ziehen, dass die Eigenschaften nicht existieren würden, und zwar in dem Sinne, dass sie eine reine Konstruktion des denkenden Subjektes wären). Diese Art Prozedere erweckt den Eindruck, dass bestimmte Komponenten der Realität einfach nicht angezweifelt werden: Die Eigenschaften sind da; deren Existenz lässt sich weder anzweifeln noch widerlegen.

${ }^{49}$ Ein Mensch kann übrigens auch in verschiedenen Zeiten nicht Mensch und nicht Mensch sein; eine Einzelentität kann nicht ihre eigene wesentliche Konstitution verlieren, es sei denn, dass sie aus dem Bereich der Existenz verschwindet. Dies würde jedoch der Fall sein, wenn Mensch nicht (mehr) Mensch wäre; falls eine Einzelentität Mensch ist, ist sie vom „MenschSein“ wesentlich determiniert. Die Konstitution kann nicht geändert werden. Der Passus Topica Delta 5, 125b37-39 kann diesbezüglich veranschaulichen, dass die wesentlichen Eigenschaften nicht verloren werden können, es sei denn, dass eine Entität aus dem Bereich der Existenz verschwindet: «Denn es ist unmöglich, dass dasselbe noch fortbesteht, falls es ganz aus der Art

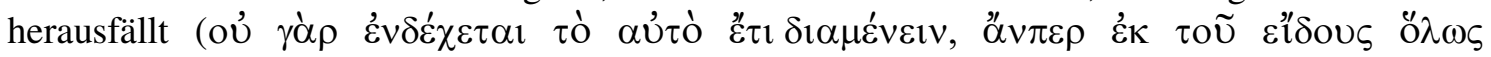



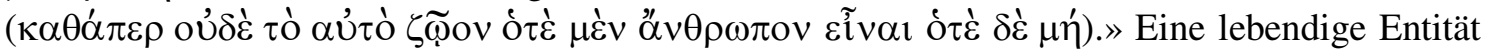
kann nicht zuerst Mensch sein, dann nicht mehr Mensch sein: Wenn eine Entität einer Art angehört, ist sie auf notwendige Art und Weise die Eigenschaften, welche die Angehörigkeit zu dieser Art determinieren, für ihre ganze Existenz. Ein Wesen und die wesentlichen Eigenschaften kommen ferner notwendig den Entitäten zu (siehe dazu Analytica Posteriora I 4, 73a34-b32; II 13, 96b1-3). 
Journal of Ancient Philosophy Vol. V 2011 Issue 2

jedweder Änderung, welche er erfahren kann; er verliert sozusagen sich selbst, falls er die eigene ontologische Konstitution verliert.

Aristoteles hat damit in seinem Manöver einen ersten Schachzug durchgeführt, und zwar in dem Sinne, dass er sich auf den Boden des Inhaltes der Eigenschaften transferiert hat, damit die akzidentiellen Sachlagen verlassend ${ }^{50}$; dieser Schachzug wird sich als ausschlaggebend erweisen. Der Gegner des Satzes vom Widerspruch lässt den Schachzug ohne Weiteres gewähren; es wird dann für ihn zu spät sein, um die Gefahr dieses Schachzuges wahrzunehmen und sich dem Schachzug selbst wirksam entgegenzusetzen. Es kann meiner Meinung nach zu Recht gesagt werden, dass dies der entscheidende Punkt ist; da hat Aristoteles eigentlich schon gewonnen, auch wenn der Gegner dies noch nicht weiß; er hat das Ass schon erlangt, und er wird es auch gut verwenden können: Denn Aristoteles hat durch diesen Schachzug die Ebene des Inhaltes der Eigenschaften und die ontologische Konstitution der Einzelentitäten erreicht, er hat nämlich die Realität in die Verteidigung hineinmanövriert.

Der weitere Verlauf seiner Argumentation wird zeigen, dass diese beiden Realitätsgefüge vom Bestehen des Satzes vom Widerspruch abhängig sind; der Zusammenbruch des Satzes vom Widerspruch würde den Zusammenfall dieser Realitätsgefüge nach sich ziehen, d.h. im Falle, dass der Gegner mit seiner Ablehnung des Satzes vom Widerspruch fortfahren würde, würde dies zur Konsequenz führen, dass es zu einem Zusammenbruch dieser Realitätsbestandteile unvermeidlich kommen würde. Der Gegner wird sich der Realität gezwungenermaßen widersetzen müssen, falls er sich dem Satz vom Widerspruch widersetzen wird. Er wird sich durch das

\footnotetext{
${ }^{50}$ Akzidentielle Verhältnisse entsprechen Zuständen, in welchen eine Einzelentität, auch wenn in verschiedenen Zeiten, $f$ und nicht $f$ sein kann (ein Mensch kann z.B. blass und dann nicht blass sein, oder umgekehrt); dies könnte in gewissem Sinne den Eindruck vermitteln, dass der Satz vom Widerspruch nicht respektiert wird. Dieser Eindruck wäre selbstverständlich falsch: Denn die Einzelentität wäre jedenfalls nicht gleichzeitig $f$ und nicht $f$, so dass der Satz vom Widerspruch auch in diesem Falle respektiert bliebe.. Wenn es aber um die Inhalte der Eigenschaften oder um die Konstitutionen der Einzelentitäten geht, nehmen diese nie widersprüchliche Eigenschaften an: Der Inhalt der Eigenschaft „Mensch-Sein“ ist nie mit seiner Negation kompatibel; die ontologische Verfassung einer Einzelentität wie die eines Menschen ist desgleichen niemals mit ihrer eigenen Negation kompatibel. Daher ist die Berücksichtigung dieser Realitätsbestandteile weitaus wirksamer als die Berücksichtigung von einfach azkidentiellen Verhältnissen, wenn es um die Erarbeitung einer Strategie zur Verteidigung des Satzes vom Widerspruch geht.
} 
Journal of Ancient Philosophy Vol. V 2011 Issue 2

aristotelische Manöver immer wieder vor dem folgenden Dilemma befinden: Entweder er akzeptiert den Satz vom Widerspruch, damit das Spiel verlierend, oder er lehnt den Satz vom Widerspruch und mit diesem gleichzeitig auch die Realität ab.

Es ist darüber hinaus meiner Ansicht nach ein tiefes Anliegen des Aristoteles, Eigenschaften und deren Konkretisierungen nacheinander zu erwähnen; an folgenden Stellen, die zitiert werden werden, wird klar werden, dass die Negation des Satzes vom Widerspruch durch das Vorliegen von bestimmten Inhalten für die Eigenschaften und zugleich durch das von den Inhalten der Eigenschaften Konstituiert-Sein seitens der Instantiationen bekämpft wird:

- Die Eigenschaften haben bestimmte Inhalte; ihnen können diese bestimmten Inhalte nicht abgestritten werden. Der Gegner des Satzes vom Widerspruch würde das Resultat erwirken, dass die Eigenschaften nicht mehr da sind.

- Die Einzelentitäten sind an sich selbst Konkretisierungen von Eigenschaften oder, anders gesagt, konkretisierte Eigenschaften: Diese Eigenschaften können ihnen nicht aberkannt werden, denn diese Eigenschaften sind ihre eigene Konstitution; fallen diese Eigenschaften weg, so fallen die Einzelentitäten weg (falls der Satz vom Widerspruch nicht gilt, tritt eine derartige Konstellation auf, als ob einer Einzelentität das entnommen würde, was ihre eigene Konstitution ist: Die Einzelentität verschwindet einfach; die Realität verliert sozusagen all die Konturen, alle Figuren, da sie keine Konstitution mehr hat; Denn jedwede Konstitution wird durch den Verfall des Satzes vom Widerspruch annulliert) ${ }^{51}$.

Ich möchte jetzt meine Analyse mit Hilfe der folgenden Stelle Metaphysica Gamma 4, 1006b11-28 fortführen:

«Es sei daher so, wie es am Anfang gesagt wurde, dass der Name etwas bezeichnet ${ }^{52}$

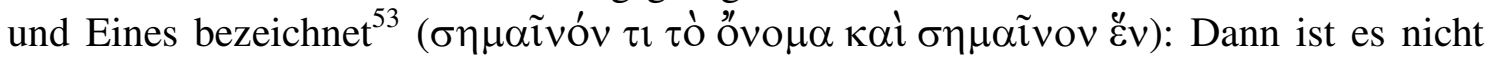

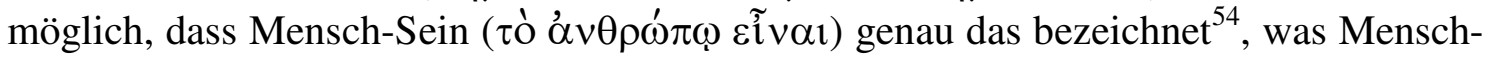

\footnotetext{
${ }^{51}$ Alles in allem hat es den Anschein, dass Aristoteles behaupten will, dass es etwas in der Realität gibt. Falls der Satz vom Widerspruch nicht gültig ist, gibt es dieses etwas nicht mehr.

52 Alternative Übersetzung für „,bezeichnet“" ,,bedeutet“.

${ }^{53}$ Alternative Übersetzung für „,bezeichnet“: ,,bedeutet“.

${ }^{54}$ Alternative Übersetzung für „,bezeichnet“" ,,bedeutet“.
} 


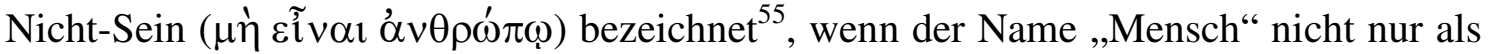
Prädikat von Einem etwas bezeichnet ${ }^{56}$, sondern auch Eines bezeichnet ${ }^{57}$ ( $\mu \grave{\eta} \mu$ óvov

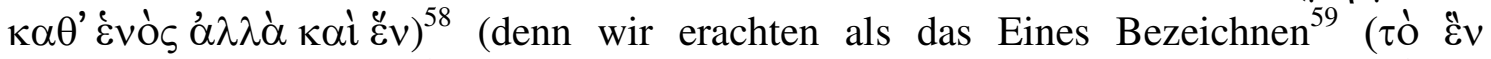

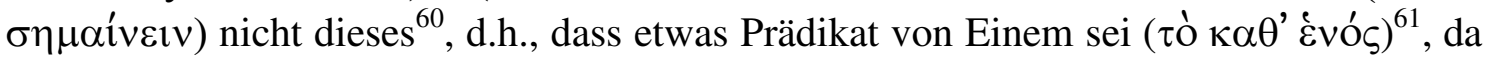
auf diese Weise mit Sicherheit sowohl der Name „gebildet“, wie der Name „weiß“, wie

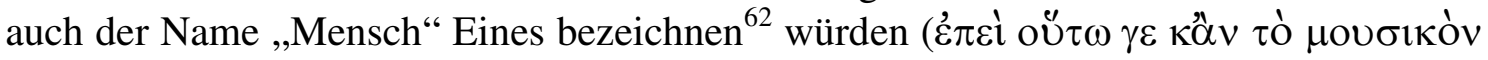

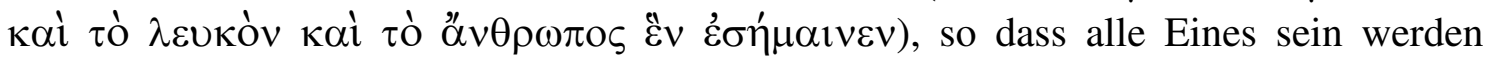

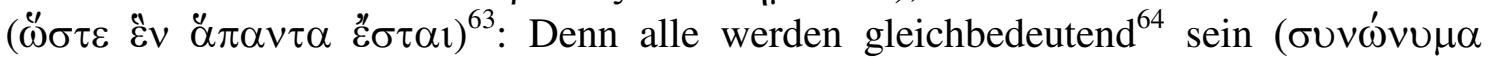

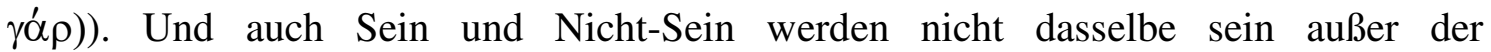

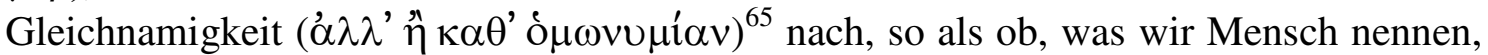
andere Nicht-Mensch nennen würden; aber der Fragepunkt ist nicht dieses, ob dasselbe

\footnotetext{
${ }^{55}$ Alternative Übersetzung für „,bezeichnet“" ,,bedeutet““.

${ }^{56}$ Alternative Übersetzung für ,bezeichnet“" ,,bedeutet“.

${ }^{57}$ Alternative Übersetzung für „,bezeichnet“" ,,bedeutet““.

${ }^{58}$ Alternative Übersetzung für „,wenn der Name „Mensch“ nicht nur als Prädikat von Einem

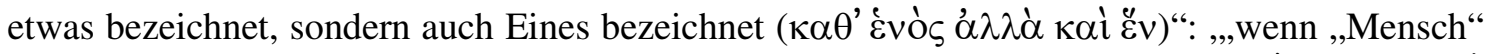

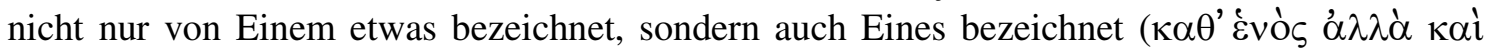
$\check{\varepsilon} v$ )“. Kirwan übersetzt z.B.: ,,if 'man' signifies not only about one thing but also one thing“
} (siehe Seite 10).

${ }^{59}$ Alternative Übersetzung für „Bezeichnen“: „Bedeuten“.

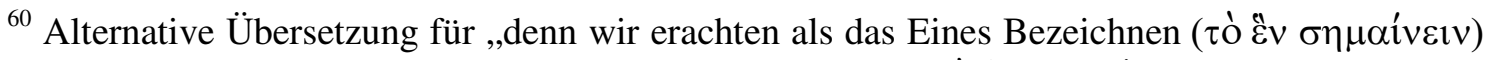

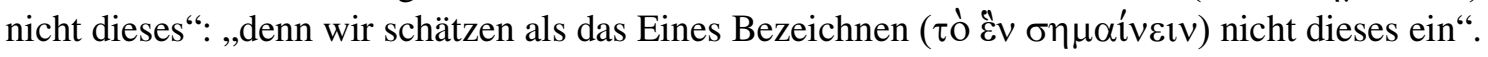

${ }^{61}$ Alternative Übersetzung für „,d.h. dass etwas Prädikat von Einem sei“: ,,das von Einem“.

${ }^{62}$ Alternative Übersetzung für „,bezeichnen“: ,,bedeuten“.

${ }^{63}$ D.h.: ,die Namen „gebildet“ und „,weiß“ und „Mensch“ Eines sein werden“. Dies würde mit sich bringen, dass die Inhalte der Eigenschaften, welche mit den Namen ,gebildet“, „weiß“ und „Mensch“ korrespondieren, dieselben sind.

${ }^{64}$ Alternative Übersetzung für „gleichbedeutend“: „synonym“. Die Textstelle Categoriae 1, 1a6-12 liefert folgende Definition für „synonym“: «Synonym werden hingegen Entitäten genannt, bei welchen sowohl der Name gemeinsam ist, wie auch der zum Namen gehörige

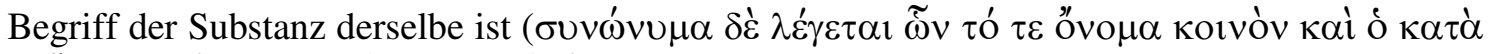

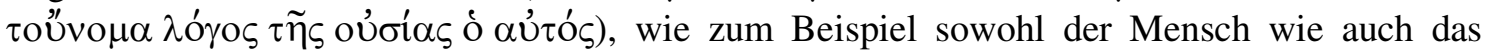
Rind ein Tier sind; denn jedes von beiden wird mit dem gemeinsamen Namen „Tier“ bezeichnet

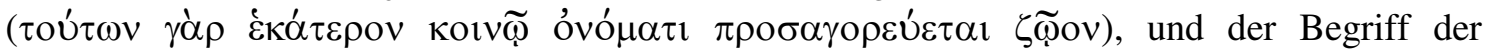

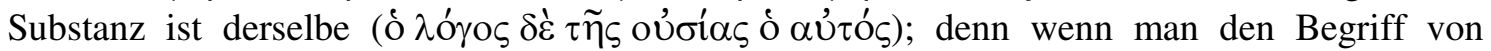
beiden angibt und sagt, was das Tier-Sein bei jedem von beiden ist, so wird man denselben Begriff ( $\tau$ òv $\alpha$ $\tau$ òv $\lambda o ́ \gamma o v$ ) angeben.» Angenommen und nicht zugegeben, dass Aristoteles mit

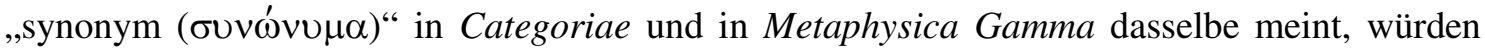
wir das folgende Ergebnis bekommen: Falls „Mensch“, „,weiß“ und „,gebildet“ synonym wären, sollten sie denselben Begriff der Substanz, d.h. dieselbe Definition haben.

\footnotetext{
${ }^{65}$ Alternative Übersetzung für „Gleichnamigkeit“: „Homonymie“.
} 
gleichzeitig Mensch sein und nicht sein kann, was den Namen betrifft ( $\tau$ ò ővo $\mu \alpha$ ), sondern, ob dasselbe gleichzeitig Mensch sein und nicht sein kann, was das Ding ${ }^{66}$ anbelangt ( $\tau$ ò $\pi \rho \tilde{\alpha} \gamma \mu \alpha)^{67}$. Wenn aber die Namen ,Mensch“ ( $\tau$ ò $\alpha ٌ v \theta \rho \omega \pi \mathrm{s}$ ) und ,Nicht-

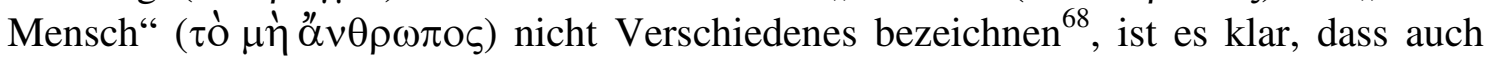

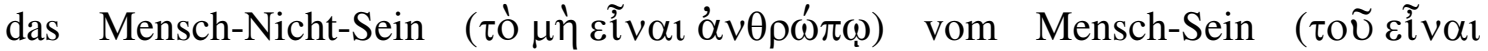

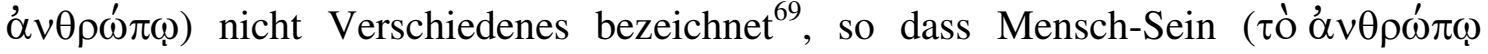

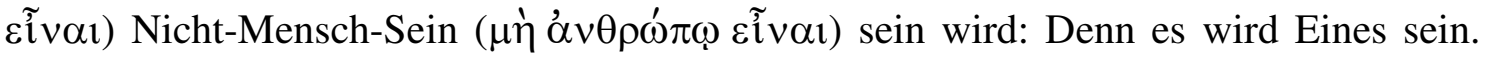
Denn dieses bedeutet das Eines Sein, wie zum Beispiel bei Gewand und Kleid, wenn der Begriff einer ist; wenn sie jedoch Eines sein werden, so bezeichnen ${ }^{70}$ das MenschSein und das Nicht-Mensch-Sein Eines. Es war aber gezeigt worden, dass es Verschiedenes bezeichnet ${ }^{71}$.»

Aus diesem Zitat geht hervor, dass der Fall des Satzes vom Widerspruch den Verfall von den Eigenschaften mit sich bringen würde: Denn Mensch-Sein und Nicht-MenschSein würden dasselbe sein. Die folgenden Punkte sollen meiner Meinung nach im Auge behalten werden:

- Eine Eigenschaft hat einen bestimmten Inhalt.

- Der Name bezeichnet eine Eigenschaft, bezieht sich auf eine Eigenschaft, welche die Essenz von bestimmten Einzelentitäten bildet. Es gilt nämlich: Ein Gemeinname (wie Mensch) hängt mit einer Eigenschaft zusammen; ein Gemeinname bezieht sich auf ein Gefüge, auf eine Abteilung der Realität, welche mit der Eigenschaft äquivalent ist. Bezeichnen ist in diesem Kontext Bezeichnen einer Eigenschaft, d.h. Bezeichnen hängt mit einer bestimmten Eigenschaft und mit einem bestimmten Komplex von Eigenschaften zusammen. Der Bezug vom Bezeichnen betrifft eine Eigenschaft.

- Das Vorliegen eines Inhaltes für eine Eigenschaft bedeutet die Inkompatibilität mit der Verneinung dieses bestimmten Inhaltes für dieselbe Eigenschaft.

\footnotetext{
${ }^{66}$ Alternative Übersetzung für „Ding“: „Sache“.

${ }^{68}$ Alternative Übersetzung für „,bezeichnet“: „,bedeutet“.

${ }^{69}$ Alternative Übersetzung für „,bezeichnet“": ,bedeutet“.

${ }^{70}$ Alternative Übersetzung für ,,bezeichnen“" ,,bedeuten“.

${ }^{71}$ Alternative Übersetzung für ,bezeichnet“": „bedeutet“.
}

${ }^{67}$ Alternative Übersetzung für „ob dasselbe gleichzeitig Mensch sein und nicht sein kann, was den Namen betrifft ( $\tau$ ò ővo $\mu \alpha$ ), sondern, ob dasselbe gleichzeitig Mensch sein und nicht sein kann, was das Ding anbelangt ( $\tau$ ò $\pi \rho \tilde{\alpha} \gamma \mu \alpha)^{\text {“: }: ~ „ o b ~ d a s s e l b e ~ g l e i c h z e i t i g ~ M e n s c h ~ s e i n ~ u n d ~ n i c h t ~}$ sein kann dem Namen nach ( $\tau$ ò ővo $\mu \alpha)$, sondern der Sache nach ( $\tau$ ò $\pi \rho \tilde{\alpha} \gamma \mu \alpha)$.“ 
Journal of Ancient Philosophy Vol. V 2011 Issue 2

Mensch-Sein kann nicht Nicht-Mensch-Sein sein. Die Inhalte stehen fest; nicht jeder Inhalt kann mit jedem Inhalt zusammenpassen.

- Die Eigenschaft determiniert die Einzelentität, welche eine Konkretisierung der Eigenschaft ist; dies gilt in dem Sinne, dass der Inhalt die Einzelentität konstituiert.

- Wenn die Einzelentität determiniert wird, muss sie dieser Inhalt sein und kann sie dieser Inhalt nicht nicht sein.

- Die Namen, mit denen die Entitäten genannt werden, können wohl variieren, die Inhalte jedoch nicht. Die Inhalte sind bestimmt und befolgen bestimmte Kompatibilitätsregeln. Die Argumentation stützt sich offensichtlich auf die Verschiedenheit und Inkompatibilität zwischen Eigenschaftsinhalten.

Das Manöver des Aristoteles an dieser Textstelle betrifft einesteils das EinesBezeichnen (oder, anders gesagt, das Eines-Bedeuten) und andernteils die Differenz zwischen dem Eines-Bezeichnen und dem Von-Einem-Bezeichnen (oder Von-EinemBedeuten). Das Eines-Bezeichnen gilt für den Inhalt einer Eigenschaft: „Mensch“ bezeichnet „zweifüßiges Tier“, da „Mensch“ sozusagen den Namen bildet, welcher für „Zweifüßiges Tier“ steht („Mensch“ ist nämlich der Name, welcher die Definition zusammenfasst); in diesem Sinne bezeichnet „Mensch“ dasselbe wie „zweifüßiges Tier".

Es lässt sich daraus ersehen, weshalb weder ,gebildet“ noch „weiß“ Eines bezeichnen, sondern nur von Einem bezeichnen können: Denn weder „gebildet“" noch „weiß“ können für „,zweifüßiges Tier“ stehen; der Inhalt der Eigenschaften „GebildetSein“ und „Weiß-Sein“ ist anders als der Inhalt der Eigenschaft „Mensch-Sein“. Darüber hinaus drücken ,gebildet“ und „weiß“ ausschließlich etwas Akzidentielles aus, falls sie auf einen Menschen bezogen werden. Durch die Einführung vom „EinesBezeichnen" hat sich Aristoteles in die Analyse der Inhalte der Eigenschaften und in die Analyse der Definition des Inhaltes der Eigenschaften versetzt ${ }^{72}$. Damit öffnet er sich

\footnotetext{
${ }^{72}$ Wie ich in gewissem Sinne in der Einführung angedeutet habe, besteht die Schwierigkeit dieses Teils der Argumentation meiner Ansicht nach darin, dass Aristoteles auf die identische Art und Weise Strukturen zu verwenden scheint, die eigentlich, wie es für „Eines-Bezeichnen“ und „Von-Einem-Bezeichnen“ der Fall ist, auf verschiedene Zusammenhänge bezogen werden sollten: Denn „Eines-Bezeichnen“ scheint dem Kontext der Definition (oder der Erklärung) des
} 
Journal of Ancient Philosophy Vol. V 2011 Issue 2

den Weg zur Erlangung von bestimmten Instrumenten, und zwar von realen Instrumenten $^{73}$ zur Verteidigung des Satzes vom Widerspruch: Denn nun verfügt er über Inhalte von Eigenschaften und von Konstitutionen von Einzelentitäten; die Erlangung dieses Niveaus ist ihm von der Unvorsichtigkeit seines Kontrahenten gegönnt worden.

Es ist in diesem Kontext unter anderem interessant, dass Aristoteles den Punkt akzentuiert, dass das Problem die Dinge, und nicht die Namen betrifft. Es sind Dinge, die nicht etwas und die Negation dieses etwas sein können. Das Thema betrifft nicht Bedeutungen von Namen, sondern Konstitutionen von Dingen. Das Problem ist nämlich nicht, ob etwas mit verschiedenen Namen (z.B. „Mensch“ oder „Nicht-Mensch“) genannt werden kann; das Problem ist vielmehr, ob ein und dieselbe Entität widersprüchliche Eigenschaften haben kann: Denn dies ist ontologisch nicht gestattet. Die Ebene der Verteidigung des Satzes vom Widerspruch ist nicht in erster Linie sprachlich, sondern ontologisch (zumindest an dieser Textstelle). Die Eigenschaften haben bestimmte Inhalte, die nicht negiert werden können.

In dieser Strategie erweist sich meiner Meinung nach als grundlegend, dass sich Aristoteles in die Perspektive des Eines-Bezeichnens versetzt: Damit will er sich meiner Meinung nach - vom Bereich der lediglich akzidentiellen Attributen entfernen; er widmet ausschließlich einesteils den wesentlichen Prädikationen und anderenteils dem Inhalt der Eigenschaften seine Aufmerksamkeit. Um den Sinn der Strategie des Aristoteles besser einzuschätzen, könnte man sich fragen, was in der Argumentation des Aristoteles passieren würde, falls Aristoteles seine Verteidigung auf eine Präposition wie

„Sokrates ist gebildet“

eingeschränkt hätte, wobei er gesagt hätte, dass es nicht der Fall sein kann, dass diese Präposition und die Präposition

„Sokrates ist nicht gebildet“

Inhaltes der Eigenschaften (Beispiel: „Mensch ist Zweifüßiges Tier“) anzugehören, während „Von-Einem-Bezeichnen“ eher dem Kontext der akzidentiellen Prädikation (Beispiel: „Dieser Mensch ist gebildet") anzugehören scheint.

${ }^{73}$ D.h. von Instrumenten, welche in der Realität eingeschrieben sind. 
Journal of Ancient Philosophy Vol. V 2011 Issue 2

zugleich wahr sein können. Auf der Basis dieser Präposition hätte er - zumindest meiner Meinung nach - in seiner Verteidigung nicht weiter prozedieren können, und zwar in dem Sinne, dass er auf Instrumente wie die Inhalte der Eigenschaften oder die Konstitutionen der Einzelentitäten hätte verzichten müssen. Zumindest hätten solche Aussagen, welche lediglich akzidentielle Verhältnisse zum Ausdruck bringen, ihm nicht dazu geholfen, sich auf die Inhalte der Eigenschaften konzentrieren zu können. Aristoteles muss seine Aufmerksamkeit auf eine andere Art von Aussagen als diejenige verschieben, welche von den akzidentiellen Aussagen gebildet ist. Durch die Berücksichtigung des Inhaltes einer Eigenschaft wie „Mensch-Sein“ wird es ihm möglich, zu illustrieren, dass das ganze Gefüge der Eigenschaften im Falle der Abwesenheit des Satzes vom Widerspruch kollabieren würde. Der Zusammenfall der Eigenschaften ist ein deutliches und ersichtliches Argument, auf dass der Zerfall des Satzes vom Widerspruch effektiv abgelehnt werden kann. Dafür muss Aristoteles seine Verteidigung des Satzes vom Widerspruch von den nicht spezifizierten Prädikationen, die auch die akzidentielle Prädikation enthalten könnten, zu den Inhalten der Eigenschaften und zum Wesensverhältnis zwischen Eigenschaften und Einzelentitäten transferieren.

Dies ist meiner Meinung nach der Grund für das Unterscheidungsmanöver zwischen dem Eines-Bezeichnen und dem Von-Einem-Bezeichnen: Während Attribute wie „gebildet“ oder „weiß“ Attribute sind, welche lediglich etwas Akzidentielles zum Ausdruck bringen, ist hingegen „Mensch“ ein Attribut, welches das Wesen von einer Entität zur Entfaltung bringt ${ }^{74}$. Falls „Eines-Bezeichnen“ und „Von-Einem-Bezeichnen“

\footnotetext{
${ }^{74}$ Dies gilt selbstverständlich, falls das zugrunde Liegende, auf welches „Mensch“ bezogen wird, ein Mensch ist: In diesem Falle stellt „Mensch“ ein essentielles Attribut für das zugrunde Liegende „Mensch“ dar, während „weiß“ eine akzidentielle Eigenschaft vom nämlichen zugrunde Liegenden „Mensch“ zum Ausdruck bringt. Eigentlich kann auch „weiß“ ein wesentliches Attribut von einem zugrunde Liegenden repräsentieren: Dies ereignet sich z.B. im Falle, dass das zugrunde Liegende, auf welches das Attribut „weiß“ bezogen wird, „weiß“ ist (siehe diesbezüglich Metaphysica Zeta 6, 1031b22-28 oder Analytica Posteriora I 22, 83a2432). Wenn daher das Attribut „Mensch“ eine wesentliche Eigenschaft des zugrunde Liegenden zur Entfaltung bringt, auf welches das nämliche Attribut bezogen wird, ist diese Position auf die Tatsache zurückzuführen, dass als zugrunde Liegendes die Entität „Mensch“ in Betracht gezogen worden ist.
} 
dasselbe wären, würden ,gebildet“, „weiß“ und „Mensch“ synonym werden. Die Argumentation funktioniert meiner Meinung nach folgendermaßen:

i. „Eines-Bezeichnen“ ist die generelle Formel für den Ausdruck des Inhaltes einer Eigenschaft.

ii. „Eines-Bezeichnen“ ist dasselbe wie „Von-Einem-Bezeichnen“.

iii. „Gebildet“, „weiß“ und „Mensch“ bezeichnen der Hypothese nach alle Eines (d.h. sie bezeichnen nicht einfach etwas von Einem; sie sind nicht akzidentielle Eigenschaften von einer Entität).

iv. Daher sind „gebildet“, ,,weiß“ und „Mensch“ Ausdruck des Wesens der Entität, auf welche sie bezogen werden (sie sind, mit anderen Worten, verschiedene Bezeichnungen für dieselbe Entität ${ }^{75}$.

v. Das Wesen einer Entität entspricht einem bestimmten und einzigen Inhalt.

vi. Folglich sind ,gebildet“, „,weiß“ und „Mensch“ die Bezeichnung für den Inhalt des Wesens, so dass sie synonym sind.

vii. Dieses Resultat ist inakzeptabel, da „gebildet“, „weiß“ und „Mensch“ nicht synonym sind und nicht synonym sein können.

Es folgt:

viii. „Eines-Bezeichnen“ und „Von-Einem-Bezeichnen“ können nicht miteinander äquivalent sein.

Im Besonderen lässt sich die Argumentation im Falle von „Mensch“ meiner Meinung nach auf die nachstehende Art und Weise zur Entfaltung bringen:

a. „Mensch“ bezeichnet Eines, d.h. „zweifüßiges Tier“.

b. „Eines-Bezeichnen“ und „Von-Einem-Bezeichnen“ sind der Hypothese nach dasselbe.

c. Auch ,gebildet“ und „weiß“ bezeichnen Eines.

d. Da „Mensch“, ,gebildet“ und „weiß“ Eines bezeichnen und auf dieselbe Entität (z.B. auf den individuellen Menschen) bezogen werden können, drücken „Mensch“, „gebildet“" und „weiß“ den nämlichen Inhalt aus.

\footnotetext{
${ }^{75}$ Eine Voraussetzung der Argumentation ist meiner Meinung nach, dass „,gebildet“, „,weiß“ und „Mensch“ alle auf dieselbe Entität bezogen werden und bezogen werden können.
} 
e. Da „Mensch“ „zweifüßiges Tier“ bezeichnet, bezeichnen auch „gebildet“ und „weiß“ ihrerseits ,zweifüßiges Tier“.

f. Daher sind „Mensch“, ,gebildet“ und „weiß“ synonym.

g. Da dieses Ergebnis inakzeptabel ist, können „Mensch“, „gebildet“ und „weiß“ nicht alle Eines bezeichnen (die Position von „Mensch“ ist anders als die Position von ,gebildet“ und „weiß“, wenn sie auf den individuellen Menschen bezogen werden).

Fazit:

h. „Eines-Bezeichnen“ und „Von-Einem-Bezeichnen“ können nicht miteinander äquivalent $\operatorname{sein}^{76}$.

Es soll diesbezüglich gesagt werden, dass die Argumentation auf unterschiedliche Art und Weise rekonstruiert werden kann; der hier Vorliegende ist nur ein Versuch und nichts mehr. Ganz unabhängig von den Rekonstruktionen, welche unternommen werden können, ist meiner Meinung nach jedoch wichtig, zu ergründen, weshalb Aristoteles den Unterschied zwischen „Eines-Bezeichnen“ und „Von-EinemBezeichnen“ einführt: Er führt meiner Ansicht nach diese Differenz ein, weil er zwischen einerseits dem Ausdruck des Inhaltes einer Eigenschaft und andererseits der Zuweisung eines einfachen akzidentiellen Attributes unterscheiden will. Der Wert der Aussage:

$$
\text { „Mensch ist zweifüßiges Tier““ }
$$

ist anders als der Wert der Aussage:

„Ein Mensch ist gebildet“.

Eine Aussage, welche eine Definition ausdrückt, ist anders als eine Aussage, in welcher eine akzidentielle Eigenschaft zugewiesen wird. Die Verschiebung auf die Ebene des Inhaltes der Eigenschaften, welche meiner Meinung nach genau durch die soeben erwähnte Unterscheidung eingeführt wird, öffnet Aristoteles den Weg zur Essenz und zur essentiellen Prädikation, welche seine Verteidigung mit stärkeren

\footnotetext{
${ }^{76}$ Bezüglich der Argumentation möchte ich in diesem Zusammenhang anmerken, dass „gebildet" und „weiß“" als ihre Bezugsentität den individuellen Menschen haben, während sich „Mensch“ auf „,Zweifüßiges Tier“ bezieht. Aristoteles scheint jedoch die drei Konzepte auf dieselbe Entität beziehen zu wollen.
} 
Journal of Ancient Philosophy Vol. V 2011 Issue 2

Instrumenten ausstatten werden, wie wir werden konstatieren können: Denn die Ablehnung des Satzes vom Widerspruch wird mit Hilfe der Konsequenzen bekämpft, welche aus der Abwesenheit des Satzes vom Widerspruch entstünden, d.h. (z.B.) die Zerstörung des Inhaltes der Eigenschaft; wäre Aristoteles auf der Ebene der Zuweisung von akzidentiellen Attributen geblieben, wie es sich im Falle der Aussage

„Sokrates ist gebildet“

ereignet, wäre Aristoteles nicht ein so starkes Argument zugunsten der Unentbehrlichkeit des Satzes vom Widerspruch zur Disposition gestanden, wie es vom Inhalt jeder Eigenschaft als solchem repräsentiert ist; jetzt hat Aristoteles ein ausschlaggebendes Argument erlangt. Denn der Zusammenbruch des Inhaltes jeder Eigenschaft bedeutet das Ende jeder Realität. Die einfache akzidentielle Prädikation kann eine derartige Argumentation nicht anbieten. Daher verschiebt Aristoteles sein Interesse auf die Eigenschaften qua Eigenschaften; er ist seinerseits praktisch dazu gezwungen, auf anderen ontologischen Ebenen als auf derjenigen, welche von der akzidentiellen Prädikation dargestellt ist, seine Instrumente zu suchen.

Bezüglich der zuletzt zitierten Stelle von Metaphysica Gamma 4, 1006b11-28 bin ich infolge der soeben dargelegten Betrachtungen nicht mit der Bemerkung von Kirwan (siehe Seite 96 seines Kommentars) einverstanden, welcher in seinem Kommentar zu den Büchern Gamma, Delta und Epsilon der aristotelischen Metaphysica die Überzeugung manifestiert, dass der Grund für die Unterscheidung zwischen ,etwas von einem bezeichnen“ und „eines bezeichnen“ nicht klar sei. Ich denke im Gegensatz dazu, dass, da Aristoteles die Gültigkeit des Satzes vom Widerspruch mithilfe der seiner Meinung nach unbezweifelbaren und unangreifbaren Existenz bestimmter Essenzen, welche den unterschiedlichen Entitäten unmittelbar eignen, verteidigen will, die Differenz zwischen essentiellen und akzidentellen Prädikationen eben in einem Kontext, welcher auf die Unausweichlichkeit des Wesens rekurrieren will, als unentbehrlich hervorkommt. Aristoteles will zeigen, dass, wenn der Satz vom Widerspruch zusammenfällt, das ganze System des Wesens kollabiert, was einem irrsinnigen Resultat gleichkäme; offensichtlich ist immer damit zu rechnen, dass Aristoteles den Schiffbruch der Essenzen als ein für jedweden Beobachter unakzeptables Resultat dahingehend erachtet, dass jeglicher Beobachter dieser Hypothese eine Abfuhr erteilen würde. 
Journal of Ancient Philosophy Vol. V 2011 Issue 2

In dieser Hinsicht stellt sich die Unterscheidung zwischen essentiellen und akzidentiellen Eigenschaften als unabdingbarer denn je heraus. Dergleichen Wichtigkeit zeigt die Betrachtung der Eigenschaften nach ihrem eigenen Inhalt, wie es für die Eigenschaft „Mensch-Sein“ der Fall ist: Denn auf diese Art und Weise wird der Inhalt der Eigenschaft in die Verteidigung eingeführt. Durch die Berücksichtigung von den Inhalten der Eigenschaften ist Aristoteles in der Lage, seine Argumentation sowohl auf diese in der Realität eingeschriebenen Gefüge, welche von den Eigenschaften repräsentiert sind, wie auch auf das Verhältnis zwischen Essenzen und Einzelentitäten zu stützen: Aristoteles hat damit das Resultat erreicht, dass er feste Strukturen der Realität in die Verteidigung hat einfügen können, und zwar in dem Sinne, dass er eine Abwehrmauer gegen die Angriffe, welche gegen den Satz vom Widerspruch gerichtet werden, hat errichten können, welche einerseits aus dem Vorhanden-Sein der Eigenschaften in der Realität und andererseits aus dem Verhältnis zwischen Eigenschaften und Einzelentitäten besteht; er hat sich, mit anderen Worten, Instrumente zur Verteidigung verschafft ${ }^{77}$, welche an sich selbst ontologischen Gefügen entsprechen. Wenn der Gegner des Satzes vom Widerspruch in seiner Abweisung der Gültigkeit des Satzes vom Widerspruch fortfahren will, muss er jetzt bereit sein, in Kauf zu nehmen, dass er als eine Konsequenz dieser Abweisung authentische Gefüge der Realität gezwungenermaßen ablehnen muss; er ist nicht mehr „,nur“ der Gegner des Satzes vom Widerspruch. Er ist jetzt zum Gegner der Realität geworden. Der Raum wird für ihn immer enger, da er am Anfang der Argumentation nicht hätte damit rechnen können, dass der Satz vom Widerspruch den Strukturen der Realität zugrunde liegt. Denn die Opposition gegen den Satz vom Widerspruch limitiert sich nicht nur auf den Satz vom Widerspruch selbst; sie ist eigentlich eine Opposition gegen die gesamte Realität.

\footnotetext{
${ }^{77}$ Dies wird durch die Analysen der weiteren Textstellen deutlicher werden: Der Punkt ist, dass der Gegner des Satzes vom Widerspruch allmählich in solch eine Lage getrieben wird, in welcher er, um die Ablehnung der Gültigkeit des Satzes vom Widerspruch beizubehalten, dazu gezwungen wird, als eine Konsequenz seiner Ablehnung auch den Inhalt der Eigenschaften, das Wesensverhältnis zwischen Eigenschaften und Einzelentitäten und die Konstitution der Einzelentitäten abzulehnen.
} 
Journal of Ancient Philosophy Vol. V 2011 Issue 2

Es ist deswegen in diesem Zusammenhang verständlich, dass einer der ersten Schritte von Aristoteles innerhalb dieses Verteidigungsmanövers in der Differenzierung zwischen akzidentellen und wesentlichen Eigenschaften und in der Unterscheidung zwischen akzidentellen und wesentlichen/definitorischen Prädikationen liegt. Die Einführung der Differenz zwischen „etwas von einem Bezeichnen“ und „eines Bezeichnen“ ist in dieses Gefüge einzuarbeiten; sie dient dazu, den Bereich des Akzidentell-Seins von der Strategie der Verteidigung zu entfernen; Aristoteles sucht feste Strukturen: Akzidenzien würden in dieser Hinsicht einfach stören. Das aristotelische Bestehen auf dem Inhalt der Eigenschaften muss infolgedessen immer richtig berücksichtigt und unterstrichen werden: Denn es bildet keine Nebenstruktur im Kontext der Verteidigung, sondern deren Basis selbst. Es scheint mir deswegen, dass Kirwan den Wert der Position der Eigenschaftsinhalte und der Essenzen innerhalb der Verteidigung des Satzes vom Widerspruch nicht in seiner Zentralität in Erwägung gezogen, sondern ganz im Gegenteil unterlassen hat. Selbstverständlich soll meine Auffassung nicht wie eine Verurteilung der Interpretation von Kirwan klingen, welche hingegen ein wertvolles und unentbehrliches Instrument zwecks der Analyse des Buches Metaphysica Gamma bildet; es ist darüber hinaus bei weitem nicht gesagt, dass meine Deutung richtig ist.

Als eine weitere Schilderung der aristotelischen Positionen über das Verhältnis von Einzelentität und Wesen kann die folgende Stelle behilflich sein. Die Stelle Metaphysica Gamma 4, 1006b28-34 besagt:

«Es ist also notwendig, dass, wenn es wahr ist, zu sagen, dass etwas Mensch ist, es

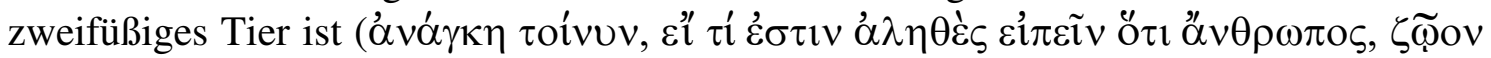

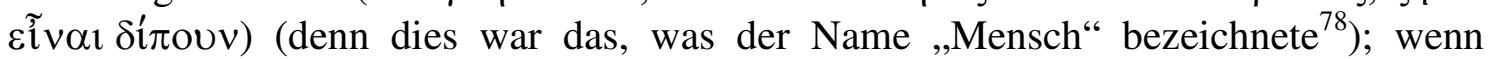

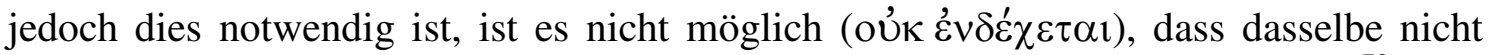

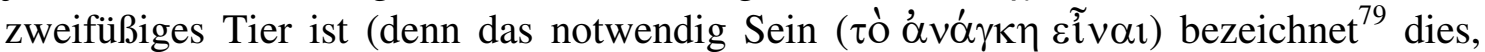

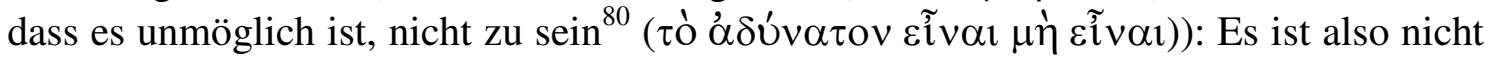
möglich, dass es gleichzeitig wahr ist, zu sagen, dass dasselbe Mensch ist und Mensch

\footnotetext{
${ }^{78}$ Alternative Übersetzung für „bezeichnete“: ,,bedeutete“.

${ }^{79}$ Alternative Übersetzung für „,bezeichnet“: „,bedeutet“.

${ }^{80}$ Alternative Übersetzung für „,dass es unmöglich ist, nicht zu sein“: „das unmöglich Sein, nicht zu sein“.
} 


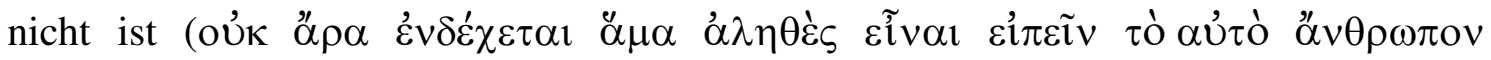

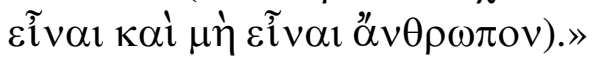

Wenn der Inhalt der Eigenschaft „Mensch“ „,Zweifüßiges Tier“ ist, bedeutet dies, dass jede Einzelentität, welche Mensch ist, zweifüßiges Tier ist. Der Inhalt ist schon bestimmt; die Einzelentität wird das Programm des Inhaltes befolgen. Diese Stelle ist insofern wichtig, als sie meiner Meinung nach veranschaulicht, wie eine Einzelentität unmittelbar etwas ist: Eine Einzelentität ist z.B. Mensch von Natur aus, so dass sie auch unmittelbar all die Eigenschaften ist, welche mit Mensch-Sein zusammenhängen. Mensch-Sein hat einen bestimmten Inhalt: Es folgt daraus, dass jegliche Einzelentität, welche diese Eigenschaft instantiiert, diesen bestimmten Inhalt instantiiert.

Auf der Basis dieser Konzeption liegt meiner Meinung nach, dass die Einzelentitäten als konkretisierte Eigenschaften interpretiert werden: Denn wenn eine Einzelentität an sich selbst eine konkretisierte Eigenschaft ist, erweist es sich als einfach unmöglich, dass sie diese Eigenschaft gleichzeitig nicht ist. Die Eigenschaften, von welchen bestimmte Einzelentitäten die Konkretisierung sind, sind das Konstitutive für diese Einzelentitäten; das Sein der Einzelentitäten besteht nämlich darin, bestimmte realisierte Eigenschaften zu sein: Dabei ist in mir die Idee aufgekommen, dass für Aristoteles die Negation dieser Konstitution die Negation der Identität einer Entität mit sich selbst wäre:

i. Wenn ein einzelner Mensch ein zweifüßiges Tier ist,

ii. wenn dieses Zweifüßiges-Tier-Sein seine eigene Konstitution ist,

iii. und wenn dieses Zweifüßiges-Tier-Sein ihm abgestritten wird,

iv. ist der einzelne Mensch als eine Folge davon nicht mehr seine eigene Konstitution, ist er nicht mehr er selbst, ist er nicht mehr mit sich selbst identisch.

Eine derartige Konstellation tritt ein, in welcher eine Einzelentität nicht mehr das ist, was ihre Identität ausmacht: Sie ist konsequenterweise nicht mehr sie selbst. Dass die Negation des Satzes vom Widerspruch die Negation der wesentlichen Identität, welche jede beliebige Einzelentität mit sich selbst hat, nach sich zieht, schwingt meiner Ansicht nach an diesen Textstellen des Aristoteles mit. Ich schlage deswegen ein Interpretationsmodell vor, gemäß welchem die Einzelentitäten als konkretisierte 
Journal of Ancient Philosophy Vol. V 2011 Issue 2

Eigenschaften vorkommen, denn meiner Ansicht nach kann genau dieses Modell das Fundament für die aristotelische Betrachtungsweise der Einzelentitäten liefern. Eine Einzelentität kommt als eine konkretisierte Eigenschaft zum Vorschein (der individuelle Mensch ist die konkretisierte Eigenschaft „Mensch-Sein“); dies heißt, dass die jeweils in Rede stehende Einzelentität nicht von dieser Eigenschaft getrennt werden kann, denn diese Eigenschaft ist für sie das Konstitutive, das Ausmachende, das Zusammenstellende. Die Einzelentität wird von der für sie wesentlichen Eigenschaft gelenkt, aufgebaut, gestiftet.

Man sollte den Unterschied zwischen wesentlichen und akzidentiellen Eigenschaften in den Unterschied zwischen konstitutiven und nicht konstitutiven Eigenschaften transferieren. Eine wesentliche Eigenschaft erweist sich bei genauerem Hinsehen als eine Beschaffenheit, welche eine Einzelentität ausmacht. Sie ist die Einzelentität, weil sie die Einzelentität zusammenstellt; eine akzidentielle Eigenschaft ist hingegen nicht wesentlich, weil sie die Einzelentität nicht konstituiert; sie bildet nicht die Einzelentität, sie ist nicht (bei den lebendigen Entitäten) eine Beschaffenheit, welche die Funktion der Einzelentität aktiviert. Mensch-Sein ist die Eigenschaft, welche die Funktionierungsweise der einzelnen Menschen enthält; dies kann für „GebildetSein" nicht gelten.

Aristoteles geht dann in seiner Analyse der Implikationen des Satzes vom Widerspruch weiter, indem er jetzt geradewegs zur Analyse der Konsequenzen überleitet, welche von der Abweisung der Gültigkeit des Satzes selbst resultieren würden: Als Konsequenz stellen sich zum Beispiel sowohl das Verschwinden der Essenz als Essenz wie auch der Zusammenbruch der Differenz zwischen Wesen und Akzidens heraus. Eine Bestätigung des Zusammenbruches des Unterschiedes zwischen Wesen und Akzidens im Falle der Annullierung des Satzes vom Widerspruch wird von der Stelle Metaphysica Gamma 4, 1007a20-1007a38 angeboten:

«Überhaupt heben diejenigen, welche diese Behauptung aufstellen, Substanz und das

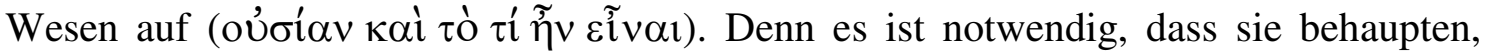

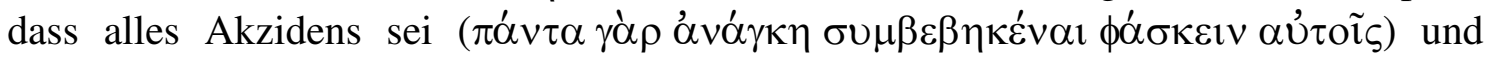

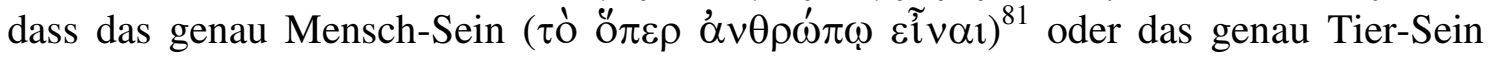

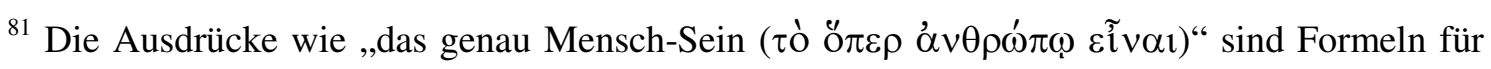
die Bezeichnung des Wesens (in diesem Falle für die Bezeichnung des Wesens vom Menschen). 
nicht existieren ${ }^{82}$. Denn wenn das, was genau Mensch ist, etwas sein wird ${ }^{83}$, wird dies nicht Nicht-Mensch-Sein oder Mensch-Nicht-Sein sein (und diese sind jedoch die Verneinungen von diesem ${ }^{84}$ ); denn Eines war es, was dieses bezeichnete ${ }^{85}$, und dies war

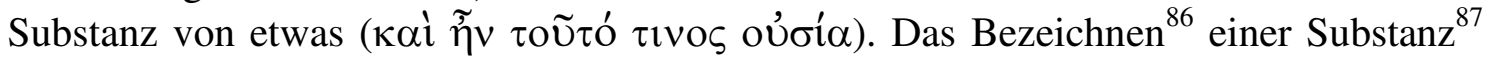

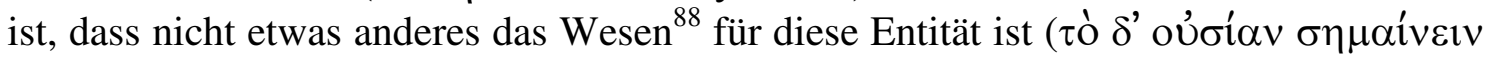

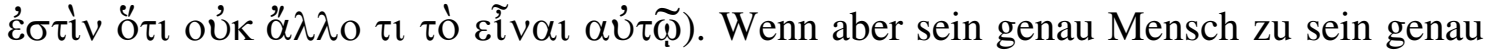

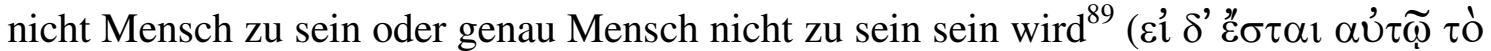

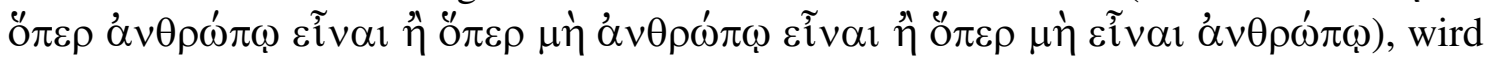
es etwas anderes sein ( $\alpha 2 \lambda \lambda \mathrm{o} \tau \imath \stackrel{\varepsilon}{\varepsilon} \sigma \tau \alpha \imath$ ), so dass es für sie notwendig ist, zu sagen, dass es von keinem Dinge einen solchen Begriff ${ }^{90}$ gebe, sondern alles dem Akzidens nach sei $(\pi \alpha ́ v \tau \alpha \kappa \alpha \tau \dot{\alpha} \sigma u \mu \beta \varepsilon \beta \eta \kappa o ́ \varsigma)^{91}$; denn dadurch sind Substanz und das Akzidens

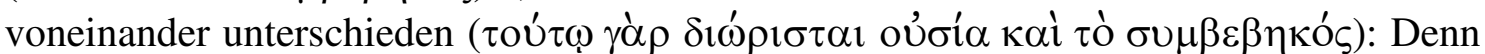
das Weiße ist ein Akzidens für den Menschen ${ }^{92}$, weil er zwar weiß ist, aber nicht das,

${ }^{82}$ Alternative Übersetzung für ,,dass das genau Mensch-Sein oder das genau Tier-Sein nicht existieren“: „dass das wesentliche Mensch-Sein oder das wesentliche Tier-Sein nicht existieren“. Ganz unabhängig von der Art und Weise, wie diese Ausdrücke übersetzt werden, kommt meiner Meinung nach aus dieser Textstelle ziemlich klar heraus, dass die Inhalte der Eigenschaften wegen des Ausfalles des Satzes vom Widerspruch zerstört werden.

${ }^{83}$ Alternative Übersetzung für „Denn wenn das, was genau Mensch ist, etwas sein wird“: „Denn wenn ein wesentliches Mensch-Sein sein wird“.

${ }^{84}$ Aristoteles bringt die Inkompatibilität zwischen Wesen und Negation des Wesens erneut zum Ausdruck, wenn sie beiden ein und derselben Entität zugewiesen werden.

${ }^{85}$ Alternative Übersetzung für „,bezeichnete“: „,bedeutete“.

${ }^{86}$ Alternative Übersetzung für „Bezeichnen“: ,Bedeuten“.

${ }^{87}$ Alternative Übersetzung für „Das Bezeichnen einer Substanz“: „Eine Substanz zu bezeichnen“, oder auch: „Das eine Substanz Bezeichnen“.

${ }^{88}$ Alternative Übersetzung für „Wesen“: ,das Sein“.

${ }^{89}$ Alternative Übersetzung für „Wenn aber sein genau Mensch zu sein genau nicht Mensch zu sein oder genau Mensch nicht zu sein sein wird“: „Wenn aber für diese Entität das wesentliche Mensch-Sein das wesentliche Nicht-Mensch-Sein oder das wesentliche Mensch-Nicht-Sein sein wird".

${ }^{90}$ D.h.: solchen Begriff des Wesens.

91 Das Resultat der Verneinung des Satzes vom Widerspruch ist das Verschwinden der Essenzen; eine Konstellation wird entstehen, in welcher alle Einzelentitäten dem Akzidens nach sind: Es sind nicht mehr Elemente in der Realität vorhanden, welche die Funktion von Essenzen versehen können, da all die wesentlichen Identifikationen und all die Zuweisungen von wesentlichen Identifikationen wegen des Zusammenfalls des Satzes vom Widerspruch negiert werden können. Der Punkt ist, dass all die Inhalte der Eigenschaften weg sind, so dass nichts mehr wesentlich identifiziert werden kann.

${ }^{92}$ Alternative Übersetzung für „Denn das Weiße ist ein Akzidens für den Menschen“: „Denn das Weiße kommt dem Menschen akzidentiell zu“. 


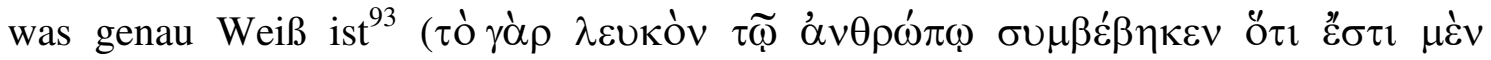

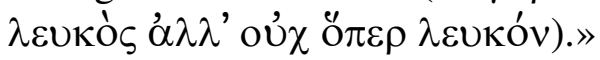

Der Kern von diesem Teil der Argumentation ist meinem Ermessen nach, dass einerseits eine Eigenschaft einen determinierten Inhalt haben soll und dass andererseits eine Einzelentität ein bestimmtes Wesen haben soll. Mensch-Sein als Eigenschaft ist anders als Nicht-Mensch-Sein oder als Mensch-Nicht-Sein; das Wesen für eine Einzelentität besteht in einem bestimmten Komplex von Eigenschaften und ist mit der Verneinung dieses selben Inhaltes inkompatibel. Falls der Satz vom Widerspruch nicht gilt, werden sowohl der Inhalt einer Eigenschaft wie auch das Wesen zerstört, weil der Inhalt von einer Eigenschaft (wie z.B. Mensch-Sein) mit dem Inhalt von „NichtMensch-Sein“ oder von „Mensch-Nicht-Sein“ identisch wird, und weil das Wesen einer Einzelentität mit seiner eigenen Negation identisch wird. Die wesentliche Identifikation jeder Einzelentität und der Inhalt jeglicher Eigenschaft gehen damit zugrunde.

Der Punkt, der meiner Ansicht nach bezüglich der ontologischen Voraussetzungen des Aristoteles in diesem Kontext am meisten erleuchtend wirkt, besteht darin, dass die Existenz von den zwei Gefügen „Wesen“ und „Substanz von etwas" als unbestreitbare Punkte gelten und gelten sollen: Aristoteles sieht (bezüglich der biologischen Entitäten) eine Welt von Essenzen vor sich, welche sozusagen die Lebensweisen der Einzelentitäten dirigieren, reglementieren und regulieren. Es sind Essenzen vorhanden: Dies bedeutet, dass bestimmte Eigenschaften ein bestimmtes Verhältnis mit bestimmten Einzelentitäten haben oder, anders gesagt, dass die Einzelentitäten als inhaltlich konstituiert gedacht werden. Die Tatsache, dass Aristoteles die Annullierung der Essenzen als inakzeptabel erachtet, bedeutet, dass er die Einzelentitäten als etwas immer auf wesentliche Art und Weise Konstituiertes einschätzt; Neutralität seitens der Einzelentitäten in Bezug auf die Eigenschaften ist keine da. Hier ist vom unmittelbaren Verschwinden der Essenz selbst die Rede, d.h. die Aufmerksamkeit des Aristoteles wendet sich der gleichzeitigen Zuerkennung eines

\footnotetext{
${ }^{93}$ Alternative Übersetzung für ,,aber nicht das, was genau Weiß ist“: ,,aber nicht das wesentliche Weiße“, oder auch: ,aber nicht das genau Weiße“. Diese Behauptung ist unter anderem deswegen interessant, weil sie auf die Existenz von Essenzen für die Entitäten hinweist, welche - wie es für die Farbe „Weiß“ der Fall ist - nicht der Kategorie der Substanz angehören.
} 
Journal of Ancient Philosophy Vol. V 2011 Issue 2

bestimmten wesentlichen Inhaltes zugunsten einer Einzelentität und der Zuerkennung der Negation dieses Inhaltes selbst zu.

Eben auf der Grundlage der Existenz und der Unbestreitbarkeit der Existenz des Wesens lässt sich eine Negation des Satzes vom Widerspruch, welche geradewegs die Abschaffung des Wesens selbst zur Folge hätte, überhaupt nicht verfechten; im Falle des Ausbleibens des Satzes vom Widerspruch würde einer selben, in Betracht gezogenen Einzelentität auch die Negation einer bestimmten wesentlichen Eigenschaft - und dies gleichzeitig - zuerteilt. Dies würde das Wesen eines Dinges unheilbar kompromittieren: Eine Einzelentität, welche die Eigenschaft „Mensch-Sein“ zugeteilt bekäme, würde auch mit der Negation des Besitzes dieser Eigenschaft ausgestattet; daher würde Sokrates zum Beispiel sowohl Mensch wie auch Nicht-Mensch sein, so dass das Konzept selbst der definierten - weil von einem genauen Eigenschaftskomplex determinierten - Einzelentität zusammenbräche: Die von den anderen Einzelentitäten dank ihren essentiellen Eigenschaften abgegrenzte Einzelentität würde einfach nicht mehr vorliegen. Die Eigenschaften würden verschwinden, weil deren Inhalt mit der Negation dieses selben Inhaltes koexistieren würde; die Einzelentitäten würden ihrerseits verschwinden, weil sie einen Komplex von wesentlichen Eigenschaften zugleich zuerkannt und aberkannt bekämen.

Es muss in einer korrekten Ontologie bestehen bleiben, dass das, was Mensch ist, d.h. der bestimmte Inhalt von Eigenschaften, die das Mensch-Sein bilden, mit der Negation von Mensch-Sein inkompatibel ist. Eine Eigenschaft wie „Mensch-Sein“ hat einen bestimmten Inhalt: Aristoteles weist der Eigenschaft eine bestimmte Komposition $\mathrm{zu}$; die Eigenschaft ist diese bestimmte Komposition und kann nichts anderes sein. Eigenschaften existieren; die ganze Struktur der Realität setzt sich aus Eigenschaften zusammen. Des Aristoteles Prozedere betrifft die Tatsache, dass alle Eigenschaften einen bestimmten Inhalt haben, und dass dieser Inhalt nicht verneint werden kann. Eigenschaften existieren und sind inhaltlich bestimmt; Aristoteles geht von dieser Gewissheit aus und verteidigt damit die Gültigkeit des Satzes: Der Zusammenbruch des Satzes bringt das Verschwinden der Eigenschaften mit sich; auf Eigenschaften zu 
Journal of Ancient Philosophy Vol. V 2011 Issue 2

verzichten, ist jedoch einfach inakzeptabel: Denn auf die Eigenschaften zu verzichten, heißt, auf die Realität selbst zu verzichten ${ }^{94}$.

Die Inhalte dieser Stelle lassen sich folgenderweise zusammenfassen:

i. Wer die Gültigkeit des Satzes vom Widerspruch ablehnt, macht die Substanz und das Wesen der Einzelentitäten zu Nichte.

ii. Im Falle der Abweisung des Satzes vom Widerspruch wird alles zum Akzidens; das Wesen als Wesen wird annulliert.

iii. Wesen und Akzidens sind eigentlich voneinander verschieden (dies kommt in einer ontologischen Auffassung zum Tragen, welche die Gültigkeit des Satzes vom Widerspruch respektiert).

iv. Das Wesen einer Einzelentität und die Substanz einer Einzelentität werden als miteinander äquivalent behandelt.

${ }^{94}$ Es könnte gegen meine Interpretation erwidert werden, dass Aristoteles eigentlich nur das Verschwinden des Wesens und nicht das Verschwinden der Eigenschaften in Aussicht stelle, falls der Satz vom Widerspruch seine Gültigkeit verliere: Denn schließlich verblieben doch die Akzidenzien; ausschließlich das Wesen gehe zugrunde. Ich würde meinerseits meine Interpretation, gemäß welcher der Fall des Satzes vom Widerspruch den Fall sämtlicher Eigenschaften mich sich bringt, dadurch verteidigen, dass, wenn wegen des Verfalls des Satzes vom Widerspruch der Inhalt jeder Eigenschaft verneint werden kann, als Folge davon jegliche Eigenschaft verschwindet (der Inhalt jeder Eigenschaft kann in der Tat zugleich behauptet und verneint werden; jedweder bestimmende Inhalt wird damit zerstört; keine Eigenschaft mehr hat mithin einen Inhalt). Als eine besondere Konsequenz des Kollabierens des gesamten Systems von Eigenschaften hat keine Einzelentität mehr eine Essenz (der einzelne Mensch ist Mensch und nicht Mensch), so dass jede Einzelentität nur Akzidenzien haben kann. Bei genauerem Hinsehen sind jedoch auch die Eigenschaften, welche den Akzidenzien entsprechen, verschwunden: Denn Weiß-Sein kann auch Eigenschaften beinhalten, die mit dem Weiß-Sein selbst inkompatibel sind. Alle Eigenschaften sind weg, denn das Bestimmt- und das Bestimmbar-Sein des Inhaltes einer Eigenschaft ist weg. Darüber hinaus gelten bestimmte Eigenschaften als Akzidenzien, eben weil sie in Bezug auf ein bestimmtes zugrunde Liegendes genommen werden: Weiß ist Akzidens im Verhältnis zu einem zugrunde Liegenden wie Mensch, denn Weiß ist nicht Teil der Essenz des Menschen. Jedoch wird genau an der Stelle, welche im Haupttext zitiert wird, gesagt, dass Weiß eine Essenz hat oder dass die Essenz vom Weiß existiert (,Denn das Weiße ist ein Akzidens für den Menschen, weil er zwar weiß ist, aber

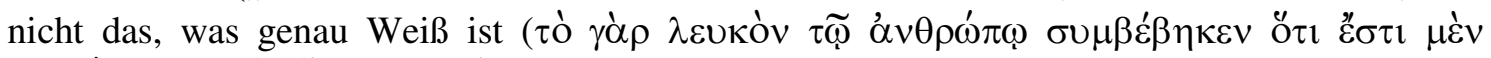

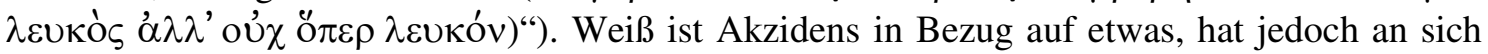
selbst eine Essenz; Weiß kann aber keinen Inhalt mehr haben, falls der Satz vom Widerspruch nicht gilt. Falls aber der Satz vom Widerspruch nicht gilt, sind alle Entitäten weg: Denn die Eigenschaften verlieren ihren eigenen Inhalt, die Einzelentitäten verlieren ihre eigene Konstitution. 
Journal of Ancient Philosophy Vol. V 2011 Issue 2

v. Etwas als Substanz von einer Einzelentität einzuordnen, heißt, dass das Wesen von dieser Einzelentität in nichts anderem liegt, damit im Besonderen meinend, dass die nämliche Einzelentität nicht zugleich die genaue Negation des ihr im Voraus zugesprochenen Wesens sein kann.

vi. Einer Einzelentität werden jedoch infolge des Verschwindens des Satzes vom Widerspruch eine Eigenschaft und die Negation dieser Eigenschaft zugleich zugemessen.

vii. Eine Einzelentität ist deswegen eine Eigenschaft, die ihr Wesen repräsentieren sollte, und zugleich die Negation dieser Eigenschaft.

viii. Die doppelte Zuweisung im Verhältnis zu derselben Einzelentität sowohl einer bestimmten Eigenschaft wie auch der Negation dieser nämlichen Eigenschaft kommt der Zerstörung des Wesens selbst gleich.

ix. Wenn das Wesen vernichtet ist, bleibt nur das Akzidens ${ }^{95}$.

Fazit:

x. Dieses Resultat ist inakzeptabel: Infolgedessen muss der Satz vom Widerspruch seine Gültigkeit behalten.

Die grundlegende Strategie der letzten Stelle ist, dass das Wesen (oder die Substanz) von einer Einzelentität die Einzelentität selbst determiniert. Eine Eigenschaft als die Substanz von einer bestimmten Einzelentität anzusehen, bedeutet all diesen Äußerungen zufolge, dass diese bestimmte Entität ihr Wesen in nichts anderem als in der Eigenschaft hat, welche als Wesen wirkt: Folglich kann die Negation der Eigenschaft, welche die Substanz dieser Einzelentität bildet, derselben Einzelentität nicht zugeschrieben werden; die Zuweisung einer bestimmten Essenz schließt die Möglichkeit aus, dass derselben Einzelentität die Negation dieser nämlichen Essenz zugeteilt werden darf. Wenn man hingegen so verfährt, dass man derselben Einzelentität genau die Negation der vom Wesen ausgedrückten Eigenschaft zuweist, und daher dieser Einzelentität die Negation des vorher zugeteilten Wesens zuerkennt, wird das Wesen der Einzelentität einfach vernichtet aus dem Grunde, weil die Einzelentität durch diese Art Prozedere vom Besitz widersprüchlicher Eigenschaften gekennzeichnet wird:

\footnotetext{
${ }^{95}$ Strikt gesagt, würde auch das Akzidens nicht bleiben, da jeder Inhalt zerstört wird.
} 
Insofern ist die Einzelentität nichts mehr an sich selbst. Also wird die Abgrenzung, die vom Wesen der Einzelentität im Verhältnis zu den andren Einzelentitäten verschafft wird, gleichsam ausgelöscht, und die Einzelentität als eine auf eine wesentliche Art und Weise identifizierte und identifizierbare Einzelentität verschwindet.

Die Verneinung des Satzes vom Widerspruch bedeutet hierauf die Zerstörung des Wesens selbst und des Systems des Wesens: Auf der Basis dieses Teiles des Argumentes steht die Auffassung, dass diese Zerstörung selbst als völlig inakzeptabel $\mathrm{zu}$ erachten ist. Der Rekurs auf die Essenz dient in dieser Perspektive dazu, ein unbestreitbares Fundament $\mathrm{zu}$ finden, dessen Anfechtung sozusagen die Vernunft anwidert: Wenn das Wesen existiert, darf der Einzelentität, welche dieses bestimmte Wesen hat, die Verneinung des Wesens selbst nicht beigemessen werden; Sokrates kann nicht, um ein konkretes Beispiel in Augenschein zu nehmen, sowohl Mensch wie auch Nicht-Mensch sein: Entweder wird die Einzelentität von einem Wesen gekennzeichnet, oder ist die Einzelentität selbst nichts. Wenn jedoch der Satz vom Widerspruch nicht gilt, so werden das Wesen und jegliche wesentliche Identifikation abgeschafft; denn einer Einzelentität können sowohl eine essentielle Eigenschaft wie auch die Verneinung derselben Eigenschaft eingeräumt werden.

Es kommt hervor, dass das Konzept des Wesens selbst einer Einzelentität nicht mehr existiert, so dass für den Beobachter genau die Möglichkeit der essentiellen Identifikation nicht mehr vorhanden ist; genereller gesagt, falls das Wesen selbst unter diesem Gesichtspunkt nicht mehr da ist, ist das Wesen als Wesen einfach nicht mehr vorhanden und nicht mehr benutzbar.

d) Schiffbruch der dem Wesen nach unterscheidbaren Pluralität von Entitäten ${ }^{96}$

Das Resultat des Kollabierens des Satzes vom Widerspruch liegt letztendlich in der Annullierung der sich auf die Essenzen stützenden Unterscheidbarkeit der Pluralität

\footnotetext{
${ }^{96}$ Diese Bezeichnung bedeutet, dass, falls der Satz vom Widerspruch zusammenfällt und dementsprechend die Essenzen zusammenbrechen, die Einzelentitäten nicht mehr auf der Basis ihrer eigenen Essenzen voneinander unterscheidbar sind: Denn die Essenzen sind verschwunden.
} 
selbst, wie von der nachstehenden Stelle Metaphysica Gamma 4, 1007b18-1008a2 bezeugt wird:

«Ferner, wenn gleichzeitig alle Widersprüche ${ }^{97}$ über dieselbe Entität wahr sind

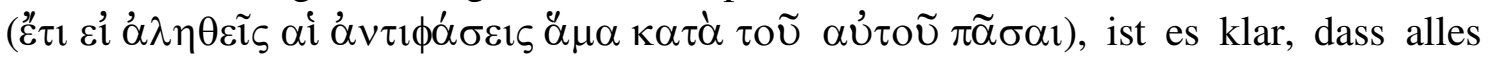

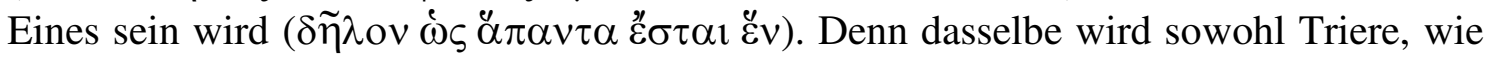

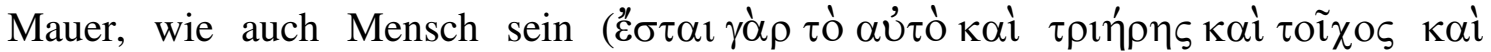
$\left.\alpha_{\alpha} v \theta \rho \omega \pi \mathrm{s}\right)^{98}$, wenn von jeder Entität etwas bejahen oder verneinen möglich ist ( $\varepsilon \dot{\imath}$

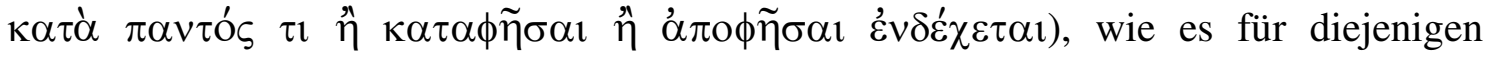
notwendig ist, welche der Lehre des Protagoras beipflichten. Denn wenn jemand meint, der Mensch sei keine Triere, so ist er auch offenbar keine Triere; also ist er auch eine Triere, wenn jedoch der Widerspruch wahr ist. Und entsteht tatsächlich die Konstellation des Anaxagoras, dass all die Dinge zusammen sind (ó $\mu$ o $\tilde{u} \alpha \dot{v} \tau \alpha$

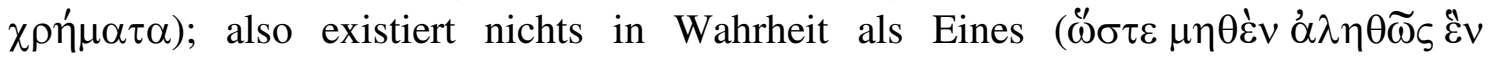

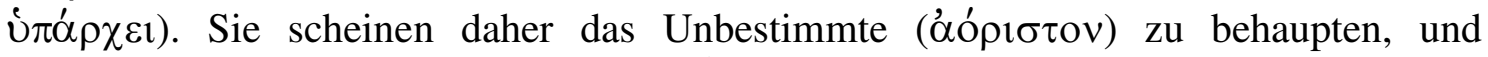
während sie glauben von dem, was ist ( $\tau$ ò ôv), zu reden, reden sie von dem, was nicht

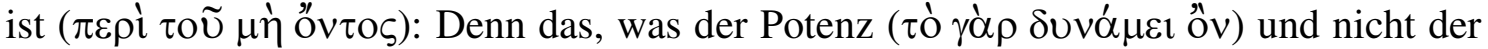

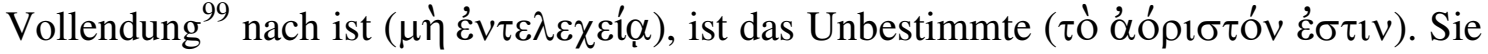
müssen jedoch allerdings von jedem Dinge die Verneinung oder die Bejahung ausdrücken: Denn es wird irrsinnig, wenn einem jeden seine eigene Verneinung zwar zukommen wird, die Verneinung eines anderen aber, das ihm nicht zukommt, nicht zukommen wird. Ich meine z.B., wenn es wahr ist, vom Menschen zu sagen, dass er nicht Mensch ist, ist es klar, dass er auch entweder Triere oder nicht Triere ist. Findet also die Bejahung statt, ist es notwendig, dass auch die Verneinung stattfindet; kommt jedoch die Bejahung nicht zu, wird sicher die Verneinung vielmehr als die Verneinung seiner selbst zukommen. Wenn daher jene zukommt, wird auch die Verneinung der Triere zukommen; wenn diese zukommt, dann wird auch die Bejahung zukommen.»

\footnotetext{
${ }^{97}$ Alternative Übersetzung für ,,alle Widersprüche“: ,,alle widersprüchlichen Aussagen“.

98 Diese Beispiele bestätigen, dass sich die gewöhnliche Realität aus Einzelentitäten zusammensetzt, welche ihrerseits die Eigenschaften ausreichend konkretisieren. Des Weiteren betrifft der Satz vom Widerspruch auch die veränderlichen Einzelentitäten; der Satz vom Widerspruch selbst ist, mit anderen Worten, nicht für die unveränderlichen Einzelentitäten reserviert. In dieser Hinsicht stimme ich der Auffassung von Lukasiewicz nicht zu, wenn er die Auffassung vertritt, dass der Satz vom Widerspruch eigentlich ausschließlich für die unveränderlichen Einzelentitäten gültig sei; dementsprechend bin ich mit Lukasiewicz nicht einverstanden, wenn er ausführt, dass der Satz vom Widerspruch eigentlich nur einen praktischen und ethischen Wert habe (siehe dazu: „Aristotle on the Law of Contradiction, in: Barnes, J. - Schofield, M. - Sorabji, R. (Hrsg.), „Articles on Aristotle. 3. Metaphysics“, Duckworth, London 1979, Seiten 50-62; ursprünglich veröffentlicht als „Über den Satz des Widerspruchs bei Aristoteles“ in: „Bulletin International de l'Académie des Sciences de Cracovie, Cl. d'histoire et de philosophie“", 1910).

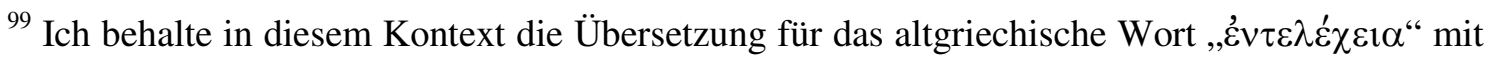
„Vollendung“ bei, obwohl ich mir davon bewusst bin, dass das Problem der Übersetzung von

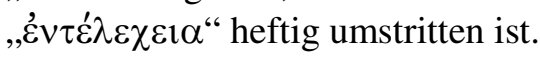


Journal of Ancient Philosophy Vol. V 2011 Issue 2

Der Unterschied zwischen den Einzelentitäten verschwindet, da eigentlich die Essenzen der Einzelentitäten selbst wegen des Zusammenbruchs des Satzes vom Widerspruch verschwunden sind: Jeder Entität kann jegliche Eigenschaft zuerkannt und aberkannt werden, so dass die Verschiedenheit zwischen den Entitäten keinen Grund zur Existenz mehr hat.

Diese Art von Ontologie sieht einfach keinen Unterschied mehr vor: Ein Mensch (oder der Mensch im allgemeinen Sinne, falls sich Aristoteles in diesem Kontext auf die Eigenschaft hat beziehen wollen) ist keine Triere und ist auch eine Triere, und so weiter: Denn dieser Prozess der Zuteilung und Aberkennung jeder beliebigen Eigenschaft in Bezug auf eine jegliche Entität lässt sich nach Belieben unendlich wiederholen. In diesem Zusammenhang ist unter anderem $\mathrm{zu}$ bemerken, dass vom Menschen gesagt werden kann, dass er nicht Mensch ist:

„Ich meine z.B., wenn es wahr ist, vom Menschen zu sagen, dass er nicht Mensch ist, ist es klar, dass er auch entweder Triere oder nicht Triere ist.".

Der einzelne Mensch wird in seinem Wesen zerstört, da er Mensch und nicht Mensch ist. Ein Mensch ist auch nicht Mensch: Die Einzelentität verschwindet, die Einzelentität ist schon verschwunden, oder sie ist sogar nie da gewesen, falls der Satz vom Widerspruch nicht da ist. Der Satz vom Widerspruch kommt in seinem Voraussetzung-Sein für das Existieren der Einzelentitäten, für das Da-Sein der Realität selbst deutlich hervor.

Die Auffassung selbst der Entität als Entität wird damit zerstört; die ontologischen Grenzen der Einzelentitäten werden damit vernichtet: Denn jede essentielle und somit auch definitorische Grenze zwischen den Einzelentitäten ist damit zum Verschwinden verurteilt; die ontologischen Grenzen zwischen den Einzelentitäten verschwinden, da die Eigenschaften, welche die wechselseitige Diversität seitens der Einzelentitäten ausmachen, verschwunden sind; ohne Eigenschaften gibt es keine Pluralität. Die Negation des Satzes vom Widerspruch wäre daher die Negation der Realität selbst, da sich die Realität aus Eigenschaften zusammensetzt, die jedoch alle verschwinden würden, falls der Satz vom Widerspruch nicht gültig wäre.

In diesem Abschnitt der Verteidigungsrede des Aristoteles stellt sich als bemerkenswert heraus, dass Aristoteles darauf hinweist, dass die Abwesenheit des 
Journal of Ancient Philosophy Vol. V 2011 Issue 2

Satzes vom Widerspruch den ontologischen Zustand des Unbestimmt-Seins bedeutet. Die Einzelentitäten können bestimmt werden und folglich voneinander verschieden sein unter der Voraussetzung, dass sie Essenzen haben: Mensch ist anders als Baum, weil seine Essenz ein anderes Programm als das Programm repräsentiert, welches von der Essenz vom Baum repräsentiert wird. Die Essenz ist unter anderem das Instrument zur wechselseitigen Differenzierung zwischen den Einzelentitäten.

Es ist zudem interessant, dass der Zustand der Unbestimmtheit dem Zustand der Potenz gleichgestellt wird, wobei darauf hingewiesen wird, dass das Unbestimmt-Sein auch die Abwesenheit vom Zustand der Vollendung, der Aktualität, des VerwirklichtSeins bedeutet. Die Gültigkeit des Satzes vom Widerspruch übt ihren Einfluss auch auf die Ebene der Zustände von Potenz und Vollendung aus: Auf dass Vollendung, Aktualität und dem Wesen nach wechselseitig unterscheidbare Pluralität vorliegen können, muss der Satz vom Widerspruch gelten. Ohne Satz vom Widerspruch gibt es kein Aktualisiert-Sein. Wir werden mit einer Realität konfrontiert, welche alle positiven Determinationen verloren hat: Nichts kann seine eigene Form, welche den Zustand des Aktualisiert-Seins repräsentiert, erreichen.

Auch dieser Teil des Argumentes bildet meines Erachtens eine Reductio ad absurdum: Im Falle nämlich, dass der Satz vom Widerspruch nicht gilt, geht auch die Pluralität selbst zugrunde; Aristoteles erwartet sich in dieser Hinsicht offensichtlich von seinem Gegner, dass der Gegner selbst nicht dazu bereit ist, diese Möglichkeit in Kauf zu nehmen, so dass der Gegner selbst die Gültigkeit des Satzes letztendlich akzeptieren muss. Es ist dabei zu bemerken, dass Aristoteles die Existenz einer Pluralität von unterschiedlichen Entitäten, und zwar von voneinander unterscheidbaren Entitäten, gleichsam als einen Ausgangspunkt der Ontologie annimmt ${ }^{100}$ : Daher wird die Annullierung der Unterscheidbarkeit der Pluralität selbst als ein inakzeptables Ergebnis des Ausfalles des Satzes vom Widerspruch bewertet. Es gilt meiner Einschätzung nach die nachstehende Struktur für diesen Teil der Argumentation:

a) Die Essenzen unterscheiden die Einzelentitäten voneinander, welchen die Essenzen selbst zugesprochen werden.

${ }^{100}$ Siehe dazu z.B. Metaphysica Beta 4, 1001a4-b1 und Metaphysica Zeta 1, 1028a10-20. 
Journal of Ancient Philosophy Vol. V 2011 Issue 2

b) Wenn der Satz vom Widerspruch nicht gilt, können alle Eigenschaften denselben Einzelentitäten gleichzeitig zugeschrieben und negiert werden: Im Besonderen lässt sich jede Essenz im Verhältnis zu jeglicher Einzelentität sowohl zuteilen wie auch absprechen.

c) Wenn es sich so verhält, werden alle Einzelentitäten zu voneinander ununterscheidbaren Einzelentitäten.

d) Mithin liegt keine authentische Pluralität im Sinne einer Pluralität vor, welche sich aus wesentlich und nicht nur numerisch verschiedenen Einzelentitäten zusammensetzt.

e) Dieses Resultat ist aber deswegen abzuweisen, weil eine Pluralität von wesentlich, und nicht lediglich numerisch voneinander verschiedenen Einzelentitäten tatsächlich vorliegt.

Es folgt:

f) Der Satz vom Widerspruch muss seine Gültigkeit behalten.

Es ist unter anderem interessant, dass Aristoteles von Unbestimmtem spricht und dieses Unbestimmte mit der Abwesenheit von definierenden Merkmalen verbindet: Eine Einzelentität ist und bleibt unbestimmt, wenn ihr die wesentlichen Eigenschaften aberkannt werden, wenn ihr, besser gesagt, die Möglichkeit selbst irgendeiner wesentlichen Bestimmung abgesprochen wird.

Dieses Argument bietet einen anderen Beweis dafür an, dass es innerhalb der Verteidigung des Satzes vom Widerspruch nicht nur um die Rettung der Rede, sondern auch und vor allen Dingen um die Rettung der Realität selbst geht: In der Tat würde die ganze Realität nicht mehr in einer differenzierten Pluralität aus dem Grunde organisiert sein, weil keine eigentliche Einzelentität im Sinne von einer im Verhältnis zu den anderen Einzelentitäten auf wesentliche Art und Weise differenzierten Einzelentität mehr vorläge und vorliegen könnte: Wenn einer Einzelentität sowohl eine Eigenschaft wie auch die Verneinung derselben Eigenschaft beigemessen werden können - und dies gilt für eine jede Eigenschaft und für jedwede Einzelentität -, ist eine jegliche Einzelentität sowohl all die Eigenschaften wie auch deren Verneinungen zugleich. Insofern stehen keine Elemente mehr zwecks der wesentlichen (und nicht lediglich numerischen) Differenzierung zwischen den Einzelentitäten zur Disposition: Denn eine 
Einzelentität müsste genau dank ihren eigenen wesentlichen Eigenschaften, welche zugleich ihre eigenen Negationen ausschließen sollten, von den anderen Einzelentitäten unterschieden werden; wenn aber alle Einzelentitäten sowohl all die Eigenschaften wie auch deren Verneinungen besäßen, wären die Einzelentitäten selbst weder voneinander unterschieden, noch voneinander unterscheidbar.

Man wäre, mit anderen Worten, in diesem ontologischen Zusammenhang nicht mehr imstande, einer Einzelentität einen differenzierenden Faktor zuzuweisen, so dass die Pluralität der Realität in ihrer Differenziertheit annulliert würde ${ }^{101}$ : Eine Einzelentität, welche alle Eigenschaften sowohl ist wie auch nicht ist, verliert ihr eigenes Wesen als Einzelentität und verschwindet als eine auf eine wesentliche Art und Weise determinierte Einzelentität aus der Realität selbst: In diesem Sinne lässt sich das Wesen als ein authentischer ontologischer Zaun werten, welcher die Einzelentität von den anderen Einzelentitäten trennt (dies gilt zumindest im Verhältnis $\mathrm{zu}$ den Einzelentitäten, welche wesentlich verschieden sind). Es kommt hinzu, dass die Realität selbst als eine tatsächlich differenzierte Realität sozusagen versinkt: Alles wird dem Wesen nach Eines, da keine Einzelentität tatsächlich unterscheidbar ist; darüber hinaus ist keine Essenz mehr vorhanden, da die Inhalte aller Eigenschaften zerstört worden sind.

\section{e) Zusammenfassung}

Wir haben jetzt die Gelegenheit gehabt, einige der Argumentationen, welche zur Verteidigung des Satzes vom Widerspruch dienen, $\mathrm{zu}$ analysieren. Aus den Betrachtungen, die wir im Laufe der Arbeit anstellen konnten, lässt sich meiner Meinung nach als Ergebnis herleiten:

\footnotetext{
${ }^{101}$ Man könnte über diesen Teil der aristotelischen Argumentation den Einwand erheben, dass in der Tat nicht die Pluralität der Einzelentitäten an sich selbst, sondern nur die Verschiedenheit zwischen den Einzelentitäten selbst annulliert wird. Gegen diesen Einwand könnte erwidert werden, dass Aristoteles der festen Überzeugung ist, dass die Einzelentitäten unmittelbar konkretisierte Eigenschaften sind: Wenn daher die Eigenschaften verschwinden, verschwinden die Einzelentitäten und mit ihnen die Pluralität.
} 
Journal of Ancient Philosophy Vol. V 2011 Issue 2

Ohne Satz vom Widerspruch keine Eigenschaft $\rightarrow$ Ohne Eigenschaft kein Wesen $\rightarrow$ Ohne Wesen keine Einzelentität.

Eigenschaften, Essenzen und Einzelentitäten verschwinden: Die Kernpunkte der aristotelischen Ontologie sind weg. Denn wenn die Inhalte der Eigenschaften negiert werden (wenn z.B. dem Mensch-Sein Komponenten verneint werden, welche das Mensch-Sein zusammenstellen sollten), verschwinden die Eigenschaften; aus dem Verschwinden der Eigenschaften folgt das Verschwinden der Essenzen; wenn zudem den Einzelentitäten die Eigenschaften abgesprochen werden, die für sie konstitutiv sind, gehen die Einzelentitäten zugrunde. Es gibt keinen Morgen mehr: Alles in der Ontologie ist definitiv verloren gegangen.

Das Ziel dieser Arbeit war es, zu zeigen, auf welche Argumente Aristoteles zurückgreift, um die Gültigkeit des Satzes vom Widerspruch zu verteidigen. Es wird an Hand all der analysierten Stellen meiner Einschätzung nach deutlich, dass Aristoteles den Satz vom Widerspruch mit der Realität selbst dahingehend verzahnt, dass sich das Bestehen des Satzes für das Bestehen der Eigenschaften, der Essenzen und der Pluralität der dem Wesen nach unterscheidbaren Einzelentitäten als unentbehrlich herausstellt.

Die Gefährlichkeit des Angriffes gegen den Satz vom Widerspruch erfordert Argumente, welche die ganze Interpretation der Realität bei Aristoteles betreffen: Der Ernst der Lage nötigt Aristoteles dazu, auf zentrale Auffassungen seiner Spekulation Rekurs zu machen.

In diesem Entwurf ist der Fokus auf die Eigenschaften, auf die Essenzen und auf das Verhältnis „Wesen-Einzelentität“ konzentriert worden: Der Verfall des Satzes vom Widerspruch würde das Verschwinden der Eigenschaften und der Einzelentitäten mit sich bringen; da jedoch dieses Ergebnis inakzeptabel ist, weil die Existenz von Eigenschaften und von Einzelentitäten, welche von den Eigenschaften aufgebaut werden, nach Aristoteles unbestreitbar ist, muss jeder Angriff gegen den Satz vom Widerspruch abgewiesen werden.

Die in diesem Entwurf analysierte Verteidigungsstrategie bildet bei weitem nicht die einzige Argumentation zur Verteidigung des Satzes vom Widerspruch: Die Analyse der weiteren Argumente können jedoch für eine andere Angelegenheit reserviert werden. 


\section{Bibliographie}

Aristoteles, De Interpretatione, übersetzt von E. Rolfes, Felix Meiner Verlag, Hamburg 1995.

Aristoteles, Erste Analytik Zweite Analytik. Herausgegeben, übersetzt, mit Einleitung und Anmerkungen versehen von Hans Günther Zekl, Griechisch-Deutsch, Felix Meiner Verlag, Hamburg 1998.

Aristoteles, Kategorien. Übersetzt und erläutert von K. Oehler. Zweite, durchgesehene Auflage, Akademie-Verlag, Berlin 1986.

Porphyrios: Einführung in die Kategorien des Aristoteles (Isagoge); Pseudo-Aristoteles: Einteilungen (Divisiones); Pseudo-Platon: Begriffsbestimmungen (Definitiones). Herausgegeben, übersetzt, mit Einleitungen und Anmerkungen versehen von Hans Günther Zekl, Felix Meiner Verlag, Hamburg 1998.

Aristoteles, Lehre vom Schluß oder Zweite Analytik, übersetzt von E. Rolfes, Felix Meiner Verlag, Hamburg 1995.

Aristoteles, Metaphysik, in der Übersetzung von H. Bonitz, mit Gliederungen, Registern und Bibliographie herausgegeben von H. Carvallo und E. Grassi, Rowohlt, Reinbek bei Hamburg 1966; auf der Grundlage der Bearbeitung von H. Carvallo und E. Grassi neu herausgegeben von U. Wolf, Rowohlt Taschenbuch Verlag, Reinbek bei Hamburg 1994.

Aristoteles, Metaphysik, in der Übersetzung von H. Bonitz, neu bearbeitet mit Einleitung und Kommentar herausgegeben von H. Seidl, griechischer Text in der Edition von W. Christ, 2 Bde., zweite, verbesserte Auflage, Felix Meiner Verlag, Hamburg 1982; dritte, verbesserte Auflage, Felix Meiner Verlag, Hamburg 1989 (erster Halbband, Bücher I-VI) - Hamburg 1991 (zweiter Halbband, Bücher VII-XIV).

Aristoteles, Metaphysik, übersetzt, mit einer Einleitung und Anmerkungen versehen von H. G. Zekl, Königshausen \& Neumann, Würzburg 2003.

Aristoteles, Metaphysik. Übersetzt und eingeleitet von T. A. Szlezák, Akademie Verlag, Berlin 2003.

Aristoteles, Peri hermeneias. Übersetzt und erläutert von H. Weidemann. Zweite, veränderte Auflage, Akademie Verlag, Berlin 2002.

Aristoteles, Topik, übersetzt von E. Rolfes, Felix Meiner Verlag, Hamburg 1995.

Aristoteles, Über die Seele. Übersetzt von Willy Theiler. Zweite, durchgesehene Auflage. Akademie-Verlag, Berlin 1966.

Aristoteles, Über die Seele. Mit Einleitung, Übersetzung (nach W. Theiler) und Kommentar herausgegeben von Horst Seidl. Griechischer Text in der Edition von Wilhelm Biehl u. Otto Apel, Felix Meiner Verlag, Hamburg 1995. 
Journal of Ancient Philosophy Vol. V 2011 Issue 2

Aristoteles, Vom Himmel. Von der Seele. Von der Dichtkunst. Übersetzt, herausgegeben und für die vorliegende Ausgabe mit einer neuen Vorbemerkung versehen von O. Gigon, Deutscher Taschenbuch Verlag, München 1987.

Aristoteles, Zweite Analytiken, mit Einleitung, Übersetzung und Kommentar herausgegeben von H. Seidl, Königshausen \& Neumann, Würzburg 1987.

Aristotelis Analytica Priora et Posteriora, Recensuit Brevique Adnotatione Critica Instruxit W. D. Ross, Praefatione Et Appendice Auxit L. Minio-Paluello, Clarendon Press, Oxford 1964.

Aristotelis Categoriae et Liber De Interpretatione. Recognovit Brevique Adnotatione Critica Instruxit L. Minio-Paluello, Clarendon Press, Oxford 1949 (1), 1992 (10).

Aristotelis De Anima, Recognovit Brevique Adnotatione Instruxit W. D. Ross, Clarendon Press, Oxford 1956.

Aristotelis Metaphysica, Recognovit Brevique Adnotatione Critica Instruxit W. Jaeger, Clarendon Press, Oxford 1957.

Aristotelis Opera, ex recensione Immanuelis Bekkeri; ed. Academia Regia Borussica; accedunt fragmenta, scholia, index aristotelicus/ addendis instruxit fragmentorum collectionem retractavit Olof Gigon, 5 Bde., de Gruyter, Berlin-West 1960-1987.

Aristotelis Topica Et Sophistici Elenchi, Recognovit Brevique Adnotatione Critica Instruxit W. D. Ross, Oxford 1958 (1). Reprinted from corrected sheets of the first edition 1963, with further corrections 1970, Clarendon Press, Oxford 1970.

Barnes, J. - Schofield, M. - Sorabji, R. (Hrsg.), Articles on Aristotle. 3. Metaphysics, Duckworth, London 1979.

Bonitz, H., Index Aristotelicus, Wissenschaftliche Buchgesellschaft Darmstadt, Darmstadt 1960. Photomechanischer Nachdruck der Ausgabe von 1870.

Brody, B., Why Settle for Anything Less than Good Old-Fashioned Aristotelian Essentialism?, in: „Nous“, 7 (1973), Seiten 351-365.

Brody, B., Identity and Essence, Princeton University Press, Princeton (N. J.) 1980.

Butchvarov, P., Resemblance and Identity: an examination of the problem of universals, Indiana University Press, Bloomington; London 1966.

Dancy, R. M., Sense and contradiction: a study in Aristotle, D. Reidel Publishing Company, Dordrecht-Holland / Boston-U.S.A. 1976.

Gutschmidt H. - Lang-Balestra, A. - Segalerba, G. (Hrsg.), Substantia - Sic et Non, Ontos Verlag, Frankfurt am Main 2008.

Hägler, R.-P., Kritik des neuen Essentialismus: logisch-philosophische Untersuchungen über Identität, Modalität und Referenz, Ferdinand Schöning, Paderborn · München · Wien · Zürich 1994.

Hicks, R. D., Aristotle, De Anima, with Translation, Introduction and Notes by R. D. Hicks, Cambridge University Press, Cambridge 1907; Georg Olms Verlag, Hildesheim . Zürich · New York 1990 (Nachdruck der Ausgabe Cambridge 1907). 
Journal of Ancient Philosophy Vol. V 2011 Issue 2

Irwin, T., Aristotle's concept of signification, in: Language and Logos. Studies in ancient Greek philosophy presented to G. E. L. Owen, edited by M. Schofield and M. C. Nussbaum, Cambridge University Press, Cambridge 1982, Seiten 241-266.

Irwin, T., Aristotle's first principles, Clarendon Press, Oxford 1988.

Kirwan, Ch., Aristotle, Metaphysics, Books $\Gamma$, 4 , and E, Clarendon Press, Oxford 1971; second edition Clarendon Press, Oxford 1993.

Kung, J., Aristotle on Thises, Suches and the Third Man Argument, in: „Phronesis“, XXVI, 3 (1981), Seiten 207-247.

Lukasiewicz, J., Aristotle on the Law of Contradiction, in: Barnes, J. - Schofield, M. Sorabji, R. (Hrsg.), Articles on Aristotle. 3. Metaphysics, Duckworth, London 1979, Seiten 50-62; ursprünglich veröffentlicht als „Über den Satz des Widerspruchs bei Aristoteles“ in: „Bulletin International de l'Académie des Sciences de Cracovie, $\mathrm{Cl}$. d'histoire et de philosophie“", 1910.

Liddell, H. G. - Scott, R., A Greek-English lexicon: with a revised supplement 1996 / compiled by H. G. Liddell and R. Scott. Rev. and augm. throughout by H. Stuart Jones, 9 ed., new suppl. added, Clarendon Press, Oxford 1996.

Liske, M.-T., Aristoteles und der aristotelische Essentialismus, Verlag Karl Alber Freiburg/München, Freiburg (Breisgau)/München 1985.

Lowe, E. J., The Four-Category Ontology. A Metaphysical Foundation for Natural Science, Clarendon Press, Oxford 2006.

Ross, W. D, Aristotle's De Anima, Edited, with introduction and commentary by David Ross, Clarendon Press, Oxford 1961, 1967 (2).

Ross, W. D., Aristotle's Metaphysics, A Revised Text with Introduction and Commentary, Clarendon Press, Oxford 1924.

Schofield, M. - M. C. Nussbaum (Hrsg.), Language and Logos. Studies in ancient Greek philosophy presented to G. E. L. Owen, Cambridge University Press, Cambridge 1982.

Segalerba, G., Aspekte der Substanz bei Aristoteles, in: Substantia - Sic et Non, herausgegeben von Gutschmidt H. - Lang-Balestra, A. - Segalerba, G., Ontos Verlag, Frankfurt am Main 2008, Seiten 35-84.

Segalerba, G., Die aristotelische Substanz als Wendepunkt in der Ontologie der Antike, in: Literaturwissenschaft als Begriffsgeschichte (Archiv für Begriffsgeschichte ·

Sonderheft 8), herausgegeben von Christoph Strosetzki, Felix Meiner Verlag, Hamburg 2010, Seiten 161-172.

Wiggins, D., Sameness and Substance, Basil Blackwell, Oxford 1980.

Wiggins, D., Sameness and Substance renewed, Cambridge University Press, Cambridge 2001. 